\title{
Cancer Stem Cell-Suppressing Activity of Chrysotoxine, a Bibenzyl from Dendrobium pulchellum ${ }^{\text {[ }}$
}

\author{
Narumol Bhummaphan, Varisa Pongrakhananon, Boonchoo Sritularak, \\ and Pithi Chanvorachote

\begin{abstract}
Inter-Department Program of Biomedical Sciences, Faculty of Graduate School, Department of Pharmacognosy and Pharmaceutical Botany; Faculty of Pharmaceutical Sciences, Department of Pharmacology and Physiology; and Cell-Based Drug and Health Product Development Research Unit, Faculty of Pharmaceutical Sciences, Chulalongkorn University, Pathumwan, Bangkok, Thailand
\end{abstract}

Received August 3, 2017; accepted November 28, 2017

\begin{abstract}
Cancer stem cells (CSCs) have been recognized as rare populations driving cancer progression, metastasis, and drug resistance in leading cancers. Attempts have been made toward identifying compounds that specifically target these CSCs. Therefore, investigations of novel therapeutic strategies for CSC targeting are required. The cytotoxic effects of chrysotoxine on human non-small cell lung cancer-derived $\mathrm{H} 460$ and $\mathrm{H} 23$ cells were evaluated by the 3-(4,5-dimethylthiazol-2-yl)-2,5-diphenyltetrazolium bromide assay. The effects of chrysotoxine suppression of CSC-like phenotypes were determined in CSC-rich populations and primary CSCs in three-dimensional (3D) culture and in an extreme limiting dilution assay. Expression of CSC markers and associated proteins was determined by Western blot analyse and flow cytometry. We have reported herein the CSC-suppressing activity of chrysotoxine, a bibenzyl compound isolated from Dendrobium pulchellum. We have shown, to our knowledge for
\end{abstract}

the first time, that chrysotoxine dramatically suppresses CSC-like phenotypes of $\mathrm{H} 460$ and $\mathrm{H} 23$ cells. Treatment with chrysotoxine significantly reduced the viability of 3D CSC-rich populations and concomitantly decreased known CSC markers. Chrysotoxine suppressed CSC phenotypes through downregulation of Src/protein kinase B (Akt) signaling. Active (phosphorylated Y416) Src was shown to regulate cancer stemness, since ectopic overexpression of Src strongly activated Akt and subsequently enhanced pluripotency transcription factor SRY (sex-determining region Y)-box 2 (Sox2)- mediating CSC phenotypes, whereas the short hairpin RNA of Src and an Src inhibitor (dasatinib) suppressed Akt, Sox2, and CSC properties. Importantly, chrysotoxine was shown to suppress active Src/Akt signaling and in turn depleted Sox2mediated CSCs. Our findings indicate a novel CSC-targeted role of chrysotoxine and its regulation by Src/Akt and Sox2, which may be exploited for cancer treatment.

\section{Introduction}

Lung cancer is one of the most challenging human cancers, due to its high rate of metastasis, therapeutic drug resistance, and high mortality rate (Peters et al., 2012). Accumulating evidence has pointed out that cancer stem cells (CSCs), unique cancer cells with capabilities of selfrenewal and pluripotency, are responsible for cancer initiation, progression, and aggression (Dalerba et al., 2007; Medema, 2013). CSCs hold the center control for heterogeneity of cancer cells in tumors as they proliferate and differentiate to other cells with a lower hierarchy of stemness line during tumorigenesis. (Dalerba et al., 2007; Medema,

This work was supported by the Grant for International Research Integration: Chula Research Scholar, Ratchadaphiseksomphot Endowment Fund; Ratchadaphiseksomphot Endowment Fund under Outstanding Research Performance Program and the Thailand Research Fund through the Royal Golden Jubilee Ph.D. program (Grant No. PHD/0033/2558).

https://doi.org/10.1124/jpet.117.244467.

S This article has supplemental material available at jpet.aspetjournals.org.
2013). In addition, the cytokines and growth factors secreted by CSCs are strictly required for maintenance of the whole tumor (Levina et al., 2008). Recently, CSC-related research has attracted tremendous attention due to a promising CSCtargeted therapy that may attenuate cancer progression and improve clinical outcomes. Some of the newly identified compounds and invented strategies are currently in preclinical and clinical evaluations (Moselhy et al., 2015).

Regarding CSC biology, several cellular signals and factors have been shown to be involved in the maintenance of cancer stemness. Among them, transcription factor SRY (sexdetermining region Y)-box 2 (Sox2) is a key regulator of the self-renewing capability of CSCs (Boumahdi et al., 2014). Sox2 is overexpressed in various cancers and is associated with cancer progression and poor prognosis (Chen et al., 2013; Lundberg et al., 2016). In particular, Sox2 is a pivotal prognostic marker that is correlated with the clinical-pathologic characteristics in lung cancer (Chou et al., 2013). Recent studies have shown that proto-oncogene tyrosine-protein kinase Src is the

ABBREVIATIONS: 3D, three-dimensional; Akt, protein kinase B; CSC, cancer stem cell; DMSO, dimethylsulfoxide; ELDA, extreme limiting dilution assay; FBS, fetal bovine serum; $\mathrm{m} / \mathrm{z}$, mass-to-charge ratio; MTT, 3-(4,5-dimethylthiazol-2-yl)-2,5-diphenyltetrazolium bromide; NF- $\kappa$, nuclear factor- $\kappa \mathrm{B}$; NMR, nuclear magnetic resonance; NSCLC, non-small cell lung cancer; PI, propidium iodide; sh, short hairpin; WST, water-soluble tetrazolium salt. 
upstream regulator of Sox2 (Wang et al., 2014). Src is a critical component in many signaling pathways that regulate survival, metastasis, and stemness characteristics (Summy and Gallick, 2003). Importantly, Src increases the cellular expression level of Sox2, the self-renewal pluripotency transcription factor in non-small cell lung cancer (NSCLC) cells (Singh et al., 2012). The activation of Src via phosphorylation at Y416 was shown to activate Akt (phosphorylation at Ser473), which is an important mediator for cell survival, proliferation, and Sox2-regulated stemness (Chen et al., 2001; Singh et al., 2012). Taken together, the cellular signals mentioned are potential molecular targets for suppressing CSC-like phenotypes.

Accumulating evidence has shown that natural products are an optimal source of bioactive compounds for anticancer drug discovery and development (Song et al., 2010, 2012). Herein, we focus on chrysotoxine, a bibenzyl compound isolated from the orchid Dendrobium pulchellum. Previous studies revealed that chrysotoxine has a cytoprotective effect against neurodegeneration in SH-SY5Y cells by attenuating 6-hydroxydopamine toxicity through mitochondria protection and nuclear factor $-\kappa \mathrm{B}(\mathrm{NF}-\kappa \mathrm{B})$ modulation (Song et al., 2010). In addition, chrysotoxine showed a protective effect against dopaminergic cell death via oxidative stress suppression, mitochondria protection, and NF- $\kappa \mathrm{B}$ modulation (Song et al., 2010, 2012). Chrysotoxine was also shown to counteract $\mathrm{NF}-\kappa \mathrm{B}$ activation by blocking its translocation to the nucleus, thereby preventing the upregulation of inducible nitric oxide synthase and intracellular nitric oxide release (Song et al., 2012).

In cancer, chrysotoxine has been shown to facilitate anoikis and attenuate the growth of lung cancer cells in an anchorageindependent condition (Chanvorachote et al., 2013). Since the effect of chrysotoxine on CSC regulation has not yet been clarified, this study aimed to investigate the effect of chrysotoxine on CSC phenotypes as well as the underlying molecular mechanism. The findings from this study could provide important insights to facilitate further investigation and development of chrysotoxine for CSC-targeted approaches.

\section{Materials and Methods}

Chemicals and Antibodies. Chrysotoxine was isolated from the stems of $D$. pulchellum and its purity was determined using high-performance liquid chromatography and nuclear magnetic resonance (NMR) spectroscopy with more than $95 \%$ purity. 3-(4,5-Dimethylthiazol-2-yl)-2,5-diphenyltetrazolium bromide (MTT), water-soluble tetrazolium salt (WST), Hoechst 33342, propidium iodide (PI), dimethylsulfoxide (DMSO), and bovine serum albumin were obtained from Sigma-Aldrich (St. Louis, MO). Primary antibodies against phosphorylated Src (Y416), total Src, phosphorylated Akt (Ser473), total Akt, Sox2, Oct4, Nanog, CD44, ATP-binding cassette subfamily G2 (ABCG2), aldehyde dehydrogenase 1A1 (ALDH1A1), and 3-phosphate dehydrogenase as well as horseradish peroxidase-labeled secondary antibodies (anti-rabbit IgG or antimouse) were purchased from Cell Signaling Technology (Danvers, MA). Prominin-1 (CD133) was obtained from Cell Applications (San Diego, CA).

General Experimental Procedures and Isolation of Chrysotoxine. Chrysotoxine ( $>95 \%$ ) was isolated from the stems of D. pulchellum. Briefly, dried, powdered stems of the plant $(500 \mathrm{~g})$ were extracted with $95 \% \mathrm{EtOH}$ at room temperature to give a crude $\mathrm{EtOH}$ extract $(50 \mathrm{~g}$ ) after removal of the solvent. The crude EtOH extract was subjected to vacuum liquid chromatography on silica gel ( $n$-hexane-EtOAc gradient) to give seven fractions (A-G). Fraction D (1.8 g) was chromatographed on a Sephadex LH-20 (GE Healthcare, Uppsala, Sweden) $\left(\mathrm{MeOH} / \mathrm{CH}_{2} \mathrm{Cl}_{2}\right.$ 1:1) to give eight fractions (D1-D8). Fraction D4 (330 mg) was separated by column chromatography (silica gel; $n$-hexaneEtOAc 7:3) to yield 26 fractions. Separation of fractions 6-9 (35 mg) was performed on silica gel ( $n$-hexane-EtOAc 7:3) to afford chrysotoxine $(11 \mathrm{mg})$. The structure of chrysotoxine was determined by analysis of its spectroscopic data (Chanvorachote et al., 2013) (Fig. 1). Brown amorphous solid; $\mathrm{C}_{18} \mathrm{H}_{22} \mathrm{O}_{5}$; electrospray ionization mass spectrometry $\mathrm{m} / \mathrm{z} 319[\mathrm{M}+$ $\mathrm{H}]^{+} ;{ }^{1} \mathrm{HNMR}\left(300 \mathrm{MHz}, \mathrm{CDCl}_{3}\right) \delta 6.75(1 \mathrm{H}, \mathrm{d}, J=8.1 \mathrm{~Hz}, \mathrm{H}-5), 6.66(1 \mathrm{H}, \mathrm{br}$ $\mathrm{d}, J=8.1 \mathrm{~Hz}, \mathrm{H}-6), 6.63(1 \mathrm{H}, \mathrm{br} \mathrm{s}, \mathrm{H}-2), 6.33\left(2 \mathrm{H}, \mathrm{s}, \mathrm{H}-2^{\prime}, \mathrm{H}-6^{\prime}\right), 3.79(12 \mathrm{H}, \mathrm{s}$, $\left.\mathrm{MeO}-3, \mathrm{MeO}-4, \mathrm{MeO}-3^{\prime}, \mathrm{MeO}-5^{\prime}\right), 2.79\left(4 \mathrm{H}\right.$, br s, $\left.\mathrm{H}_{2}-\alpha, \mathrm{H}_{2}-\alpha^{\prime}\right) ;{ }^{13} \mathrm{C} \mathrm{NMR}$ $\left(75 \mathrm{MHz}, \mathrm{CDCl}_{3}\right) \delta 148.5(\mathrm{C}-4), 147.0(\mathrm{C}-3), 146.6\left(\mathrm{C}-3^{\prime}, \mathrm{C}-5^{\prime}\right), 134.1$ (C-1), 132.7 (C-4'), 132.5 (C-1'), 120.1 (C-6), 111.8 (C-2), 111.1 (C-5), 105.0 (C-2', C-6'), $56.0(\mathrm{MeO}-3), 55.8\left(\mathrm{MeO}-3^{\prime}, \mathrm{MeO}-5^{\prime}\right), 55.5(\mathrm{MeO}-4), 37.9(\mathrm{C}-\alpha)$, and $37.4\left(\mathrm{C}-\alpha^{\prime}\right)$.

In this experiment, chrysotoxine was prepared as a master stock solution in DMSO, which was further diluted with cell culture medium to the desired concentration. The final concentration of DMSO was less than $0.1 \%$, which is not harmful to the cells.

Cell Culture. Human NSCLC cell lines NCI-H460 and NCI-H23 and human keratinocyte HaCaT cells were obtained from the American Type Culture Collection (Manassas, VA). NCI-H460 and NCI-H23 cells were cultivated in RPMI 1640 medium supplemented with $10 \%$ fetal bovine serum (FBS), $2 \mathrm{mM}$ L-glutamine, and $100 \mathrm{U} / \mathrm{ml}$ penicillin and streptomycin, whereas HaCaT cells were maintained in Dulbecco's modified Eagle's medium supplemented with 10\% FBS, $2 \mathrm{mM}$ L-glutamine, and $100 \mathrm{U} / \mathrm{ml}$ penicillin and streptomycin. Cell cultures were maintained in a $37^{\circ} \mathrm{C}$ humidified incubator with $5 \%$ $\mathrm{CO}_{2}$. Cells were passaged at $80 \%$ confluent density using a $0.25 \%$ trypsin solution supplemented with $0.53 \mathrm{mM}$ EDTA. RPMI 1640 medium, FBS, L-glutamine, penicillin/streptomycin, phosphate-buffered saline, trypsin, and EDTA were obtained from Gibco (Grand Island, $\mathrm{NY}$ ).

Enriched primary NSCLC stem cells were obtained from Promab Biotechnologies Inc. (Richmond, CA). Cells were cultivated in CSC premium media (catalog number 20101) supplemented with $10 \%$ FBS, $100 \mathrm{U} / \mathrm{ml}$ penicillin and streptomycin, and $2 \mathrm{mM}$ L-glutamine.

Cytotoxicity Assay. For the cytotoxicity assay, cells were seeded onto 96-well plates at a density of $1 \times 10^{4}$ cells/well and allowed to adhere by incubation overnight. Cells were then treated with various concentrations of chrysotoxine and analyzed for cell viability using the

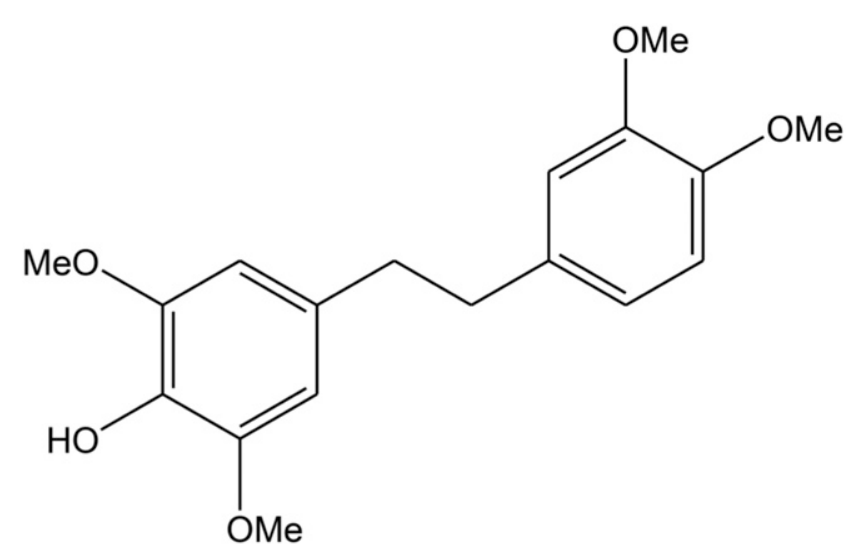

\section{Chrysotoxine}

Fig. 1. The chemical structure of chrysotoxine (Chanvorachote et al., 2013). 

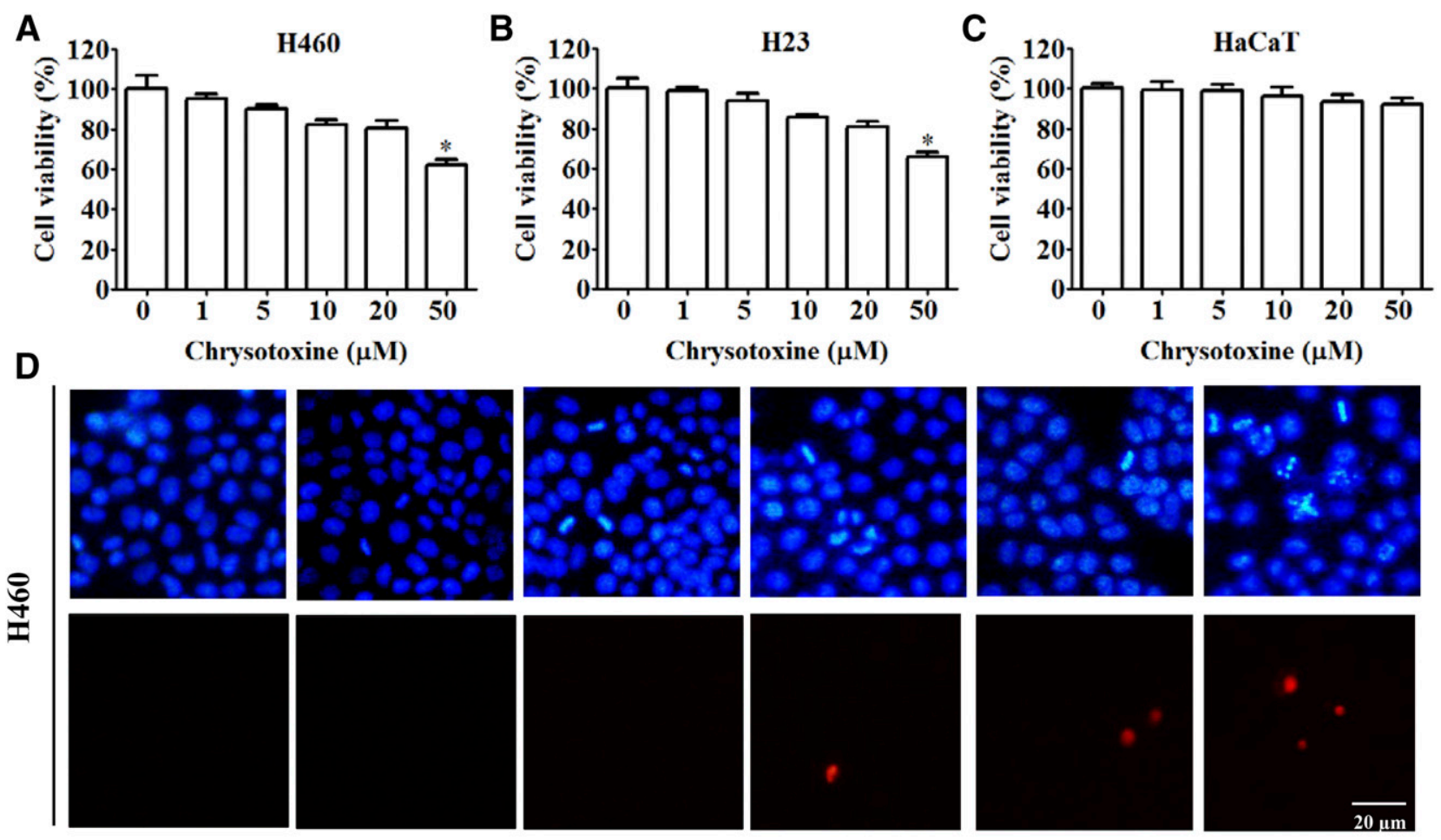

0

1

5
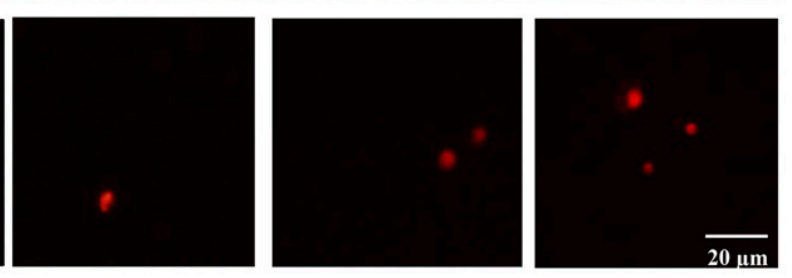

10

20

50

Chrysotoxine $(\mu \mathrm{M})$

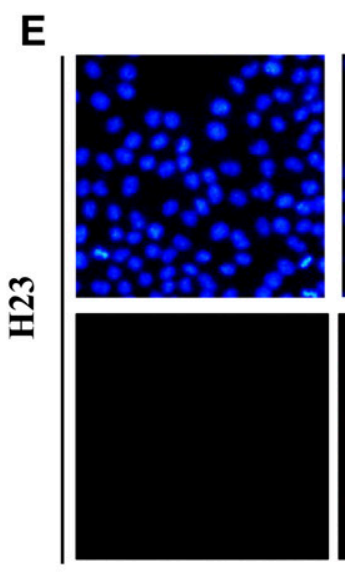

0

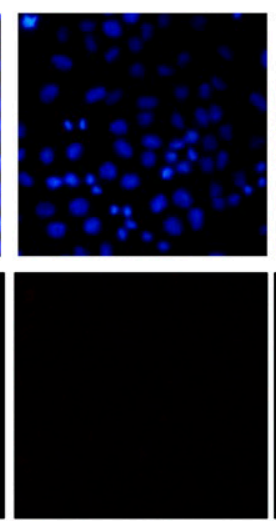

1
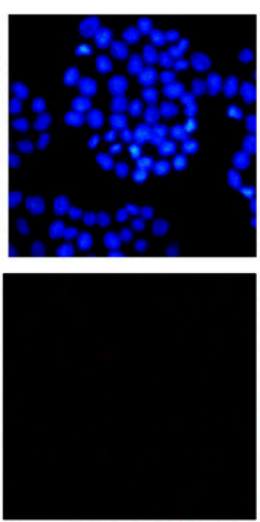

5

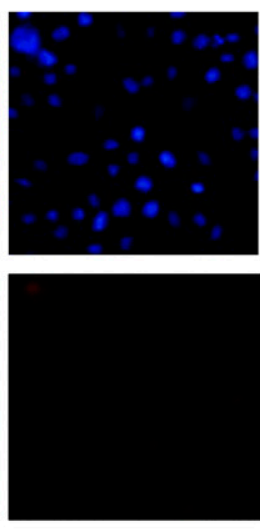

10

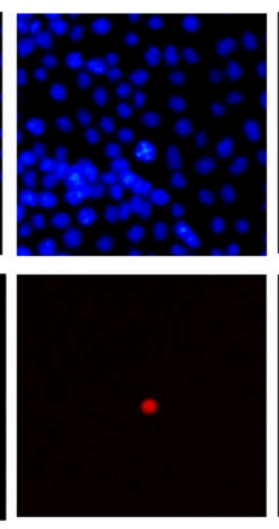

20
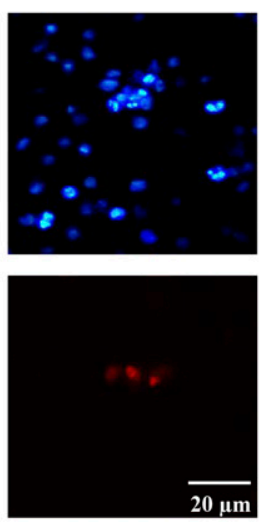

50

\section{Chrysotoxine $(\mu \mathrm{M})$}

$\mathbf{F}$

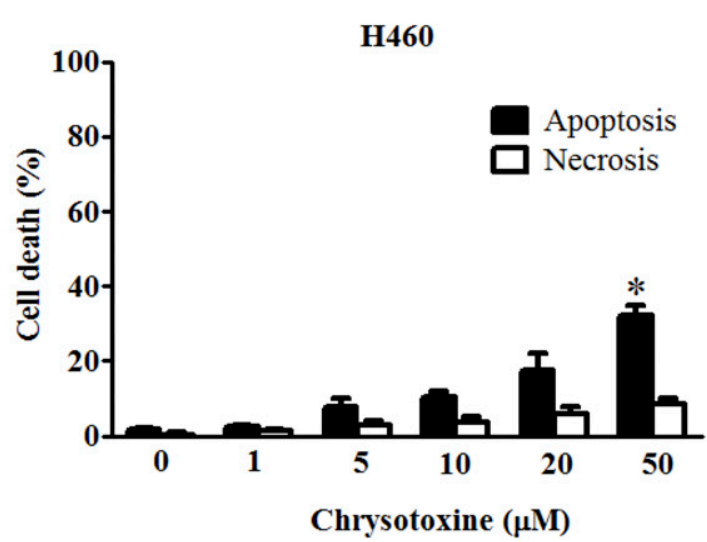

G

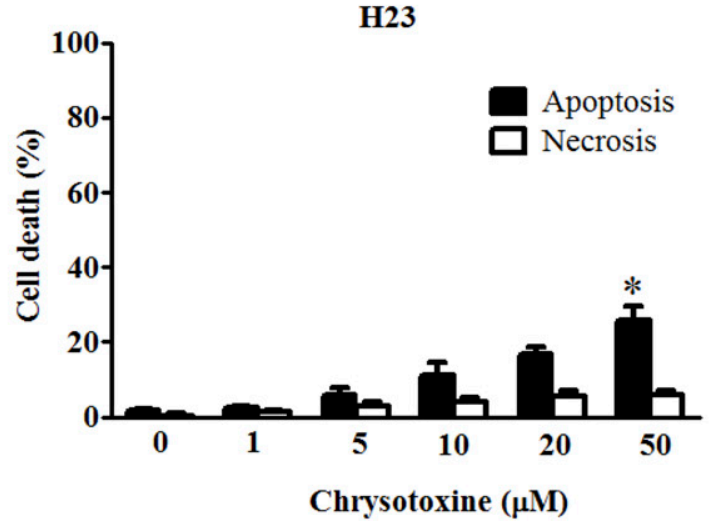

Fig. 2. Cytotoxic effect of chrysotoxine on human lung cancer H460 and H23 cells. (A-C) H460 (A), H23 (B), and HaCaT (C) cells were treated with various concentrations of chrysotoxine $(0-50 \mu \mathrm{M})$ for 24 hours or solvent was used as the control group, and cell viability was then determined by the MTT assay, relative to the viability of untreated cells set as $100 \%$. (D-G) The level of apoptotic and necrotic cell death was evaluated at the same time using Hoechst $33342 /$ PI costaining and is shown relative to that of the control cells. All plots show the mean \pm S.D. $(n=4) * P<0.05$ vs. untreated cells. 
A

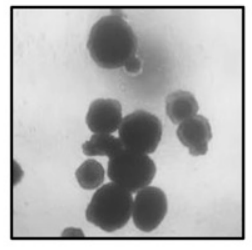

0

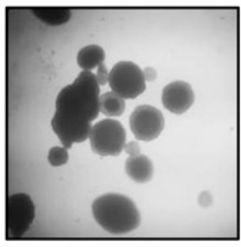

1

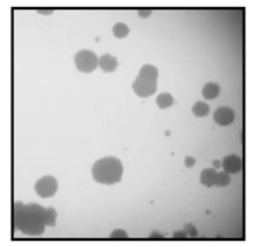

5

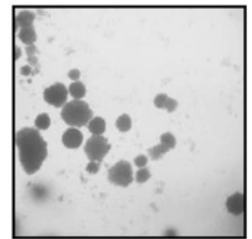

10

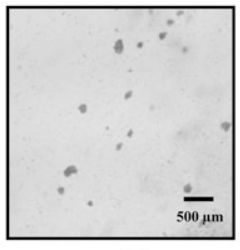

20

Chrysotoxine $(\mu \mathrm{M})$

B

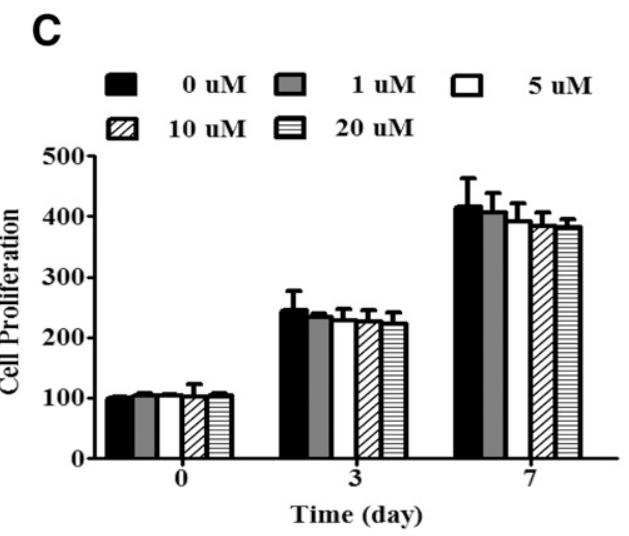

D

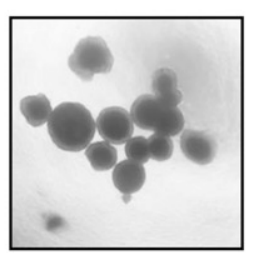

$\mathbf{0}$

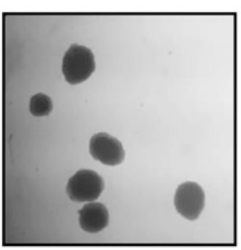

1

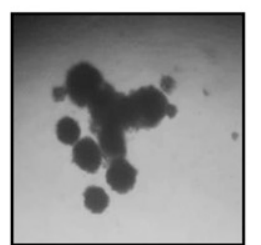

5

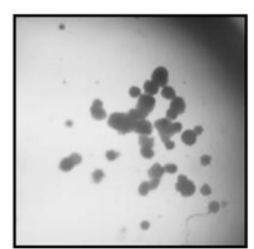

10

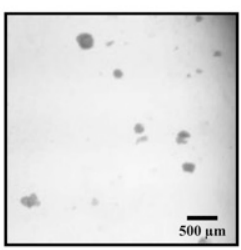

20

\section{Chrysotoxine ( $\mu \mathrm{M})$}

E

$\mathbf{F}$
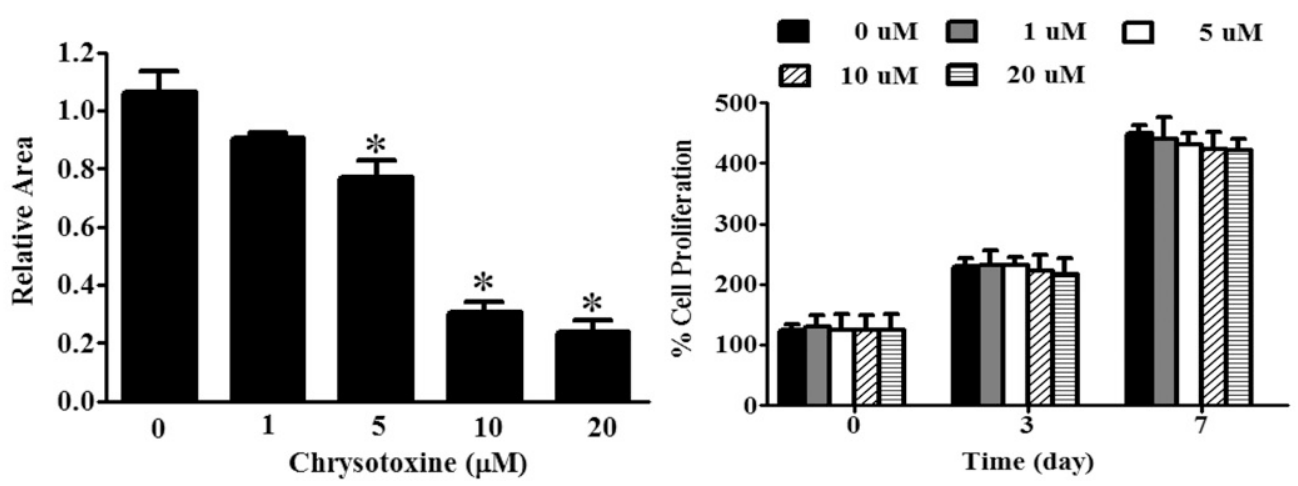

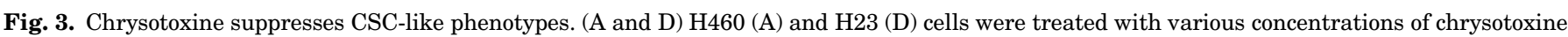

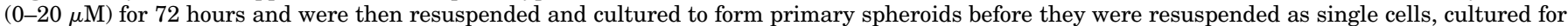

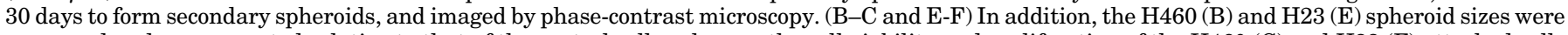

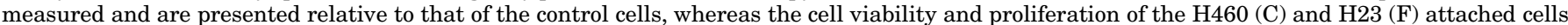

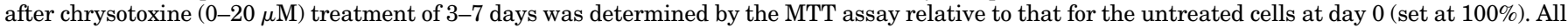
plots show the mean \pm S.D. $(n=4)$. $* P<0.05$ vs. untreated cells. Original magnification, $4 \times$ in $(A)$ and $(\mathrm{D})$. 

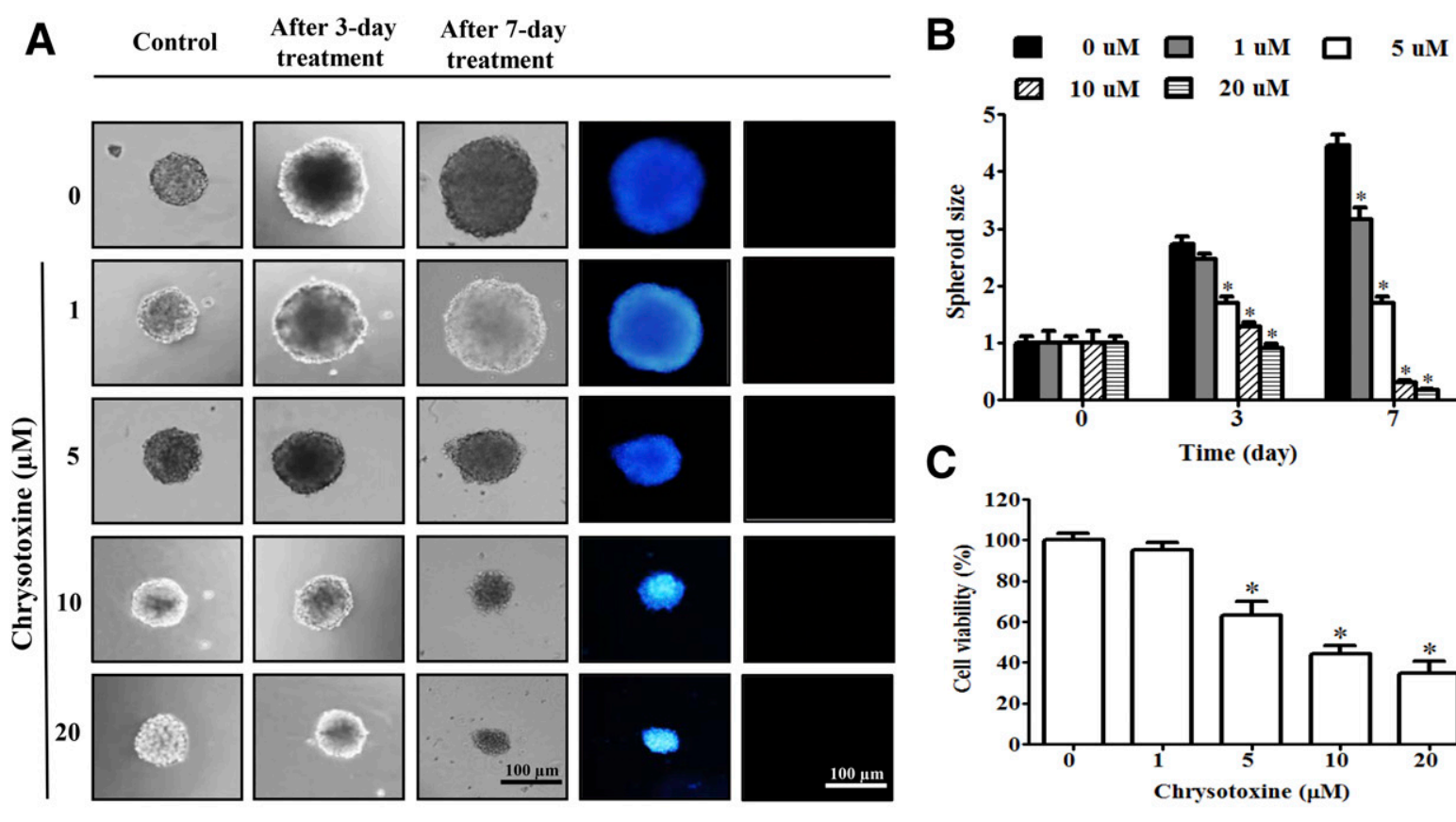

D
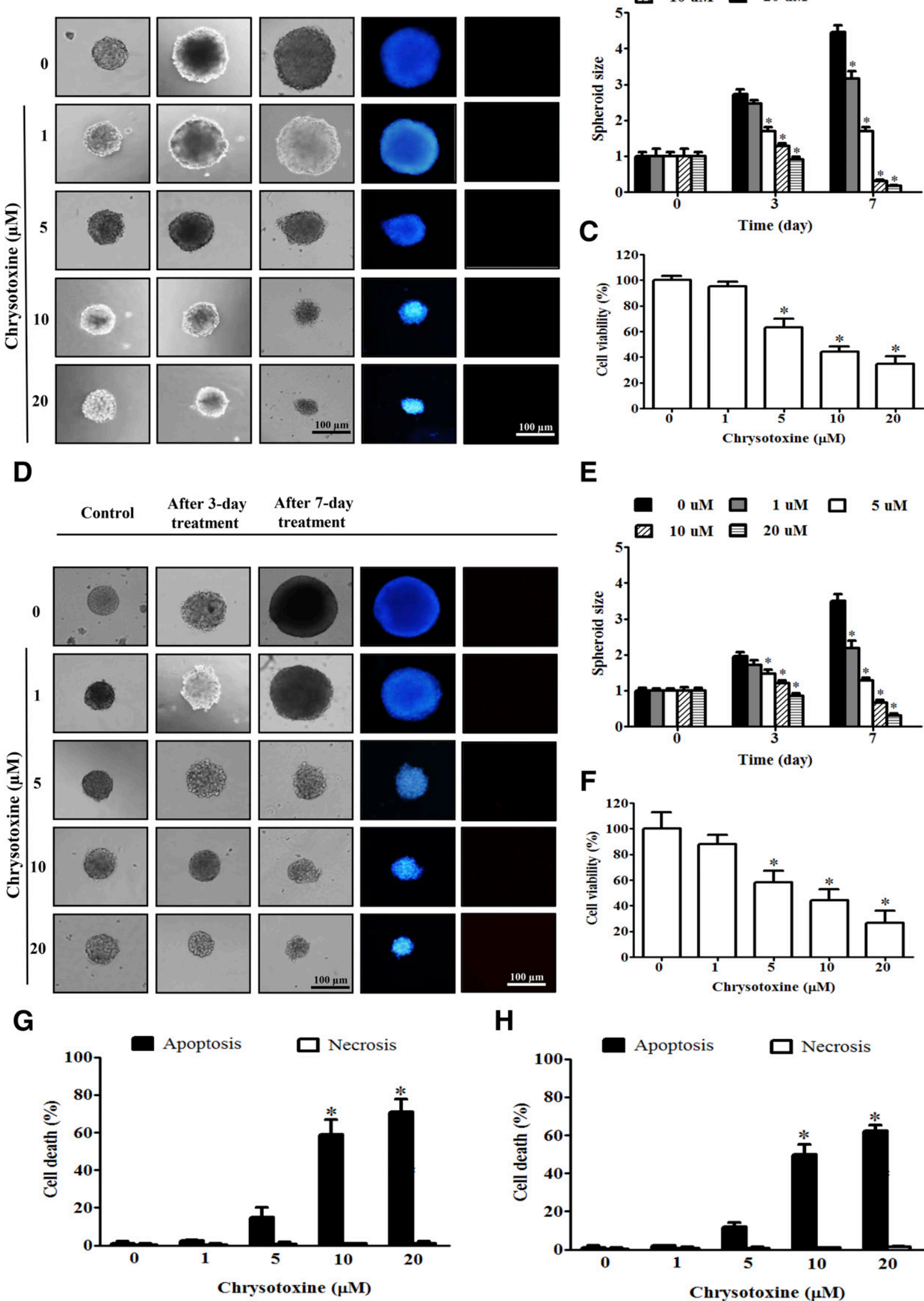

E
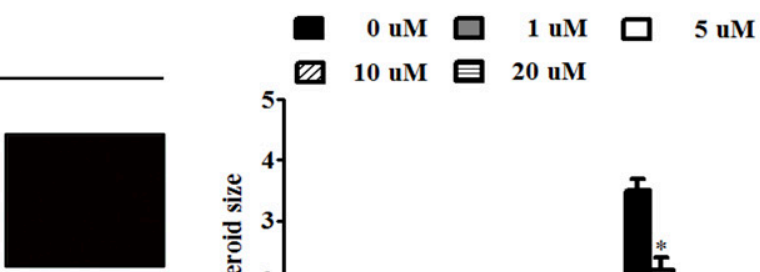

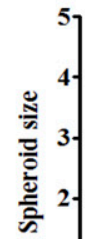
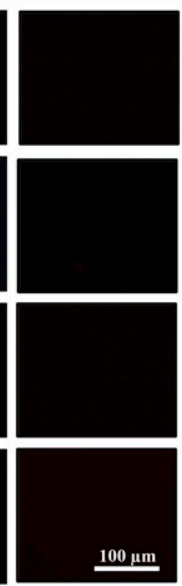

F

H

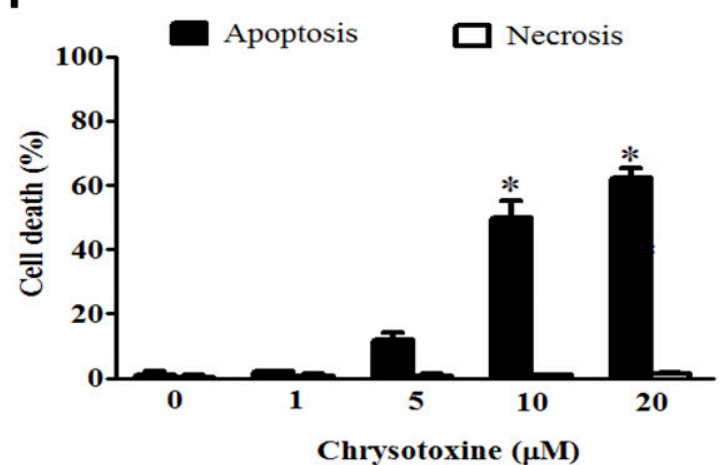


MTT assay. Cells were incubated with MTT $(500 \mu \mathrm{g} / \mathrm{ml})$ for 4 hours at $37^{\circ} \mathrm{C}$ and the intensity of formazan product, after solubilization in $100 \mu \mathrm{l} \mathrm{DMSO}$, was determined at $570 \mathrm{~nm}$ using a microplate reader (Anthros, Durham, NC). Relative cell viability was calculated by dividing the absorbance of the treated cells by that of the control cells. The half-maximal inhibition concentration $\left(\mathrm{IC}_{50}\right)$ was determined from four independent experiments using GraphPad Prism 5.0 software (GraphPad Inc., La Jolla, CA).

Cell Proliferation Assay. For the cell proliferation assay, cells were seeded onto 96 -well plates at a density of 500 cells/well and were incubated overnight. Cells were then treated with various concentrations of chrysotoxine for the indicated times in $0.8 \%$ methylcellulosebased serum-free medium (Stem Cell Technologies, Vancouver, BC, Canada) supplemented with $20 \mathrm{ng} / \mathrm{ml}$ epidermal growth factor (BD Biosciences, San Jose, CA), $4 \mathrm{mg} / \mathrm{ml}$ insulin, and basic fibroblast growth factor (Sigma-Aldrich). Cell viability was analyzed using the MTT assay as above.

Cell Death Evaluation. Costaining with Hoechst 33342 and PI (both from Molecular Probes Inc., Eugene, OR) was used to determine the level of apoptotic and necrotic cell death. After the treatments, cells were stained with $10 \mathrm{mM}$ Hoechst and $5 \mathrm{mg} / \mathrm{ml} \mathrm{PI}$ for 30 minutes at $37^{\circ} \mathrm{C}$ and then cells were visualized and imaged by fluorescence microscopy (Olympus IX 51 with DP70; Olympus, Tokyo, Japan).

Spheroids Formation Assay. Cells were pretreated with chrysotoxine $(0-20 \mu \mathrm{M})$ for 72 hours and assigned to spheroids using a previously described method with modifications (Kantara et al., 2014; Condello et al., 2015; Yongsanguanchai et al., 2015; Grun et al., 2016; Jeong et al., 2017). Approximately $2.5 \times 10^{3}$ cells/well were seeded onto a 24-well ultralow attachment plate in $0.8 \%$ methylcellulose-based serum-free medium supplemented with $20 \mathrm{ng} / \mathrm{ml}$ epidermal growth factor, $4 \mathrm{mg} / \mathrm{ml}$ insulin, and basic fibroblast growth factor for 7 days. Primary spheroids were then resuspended as single cells, and again $2.5 \times 10^{3}$ cells/well were seeded onto a 24 -well ultralow attachment plate in $0.8 \%$ methylcellulose-based serum-free medium supplemented with $20 \mathrm{ng} / \mathrm{ml}$ epidermal growth factor, basic fibroblast growth factor, and $4 \mathrm{mg} / \mathrm{ml}$ insulin. Secondary spheroids were allowed to form for 30 days and spheroid formation was observed and imaged using a phase-contrast microscope (Olympus 1X51 with DP70).

For CSC-rich population establishment, the spheroid culture assay used in this study was slightly modified from a previously described method (Cao et al., 2011; Bao et al., 2013; Thakur et al., 2015; Weiswald et al., 2015; Yongsanguanchai et al., 2015; Phiboonchaiyanan et al., 2016; Shaheen et al., 2016). Cells were seeded onto a 24-well ultralow attachment plate, with approximately $2.5 \times 10^{3}$ cells/well in $0.8 \%$ methylcellulose-based serum-free medium supplemented with $20 \mathrm{ng} / \mathrm{ml}$ epidermal growth factor, basic fibroblast growth factor, and $4 \mathrm{mg} / \mathrm{ml}$ insulin. The primary spheroids were allowed to form for 7 days. At day 7 of primary spheroid culture, primary spheroids were resuspended into single cells using $1 \mathrm{mM}$ EDTA, and again $2.5 \times 10^{3}$ cells/well were seeded onto a 24 -well ultralow attached plate. Secondary spheroids were allowed to form for 14 days and were observed using phasecontrast microscopy.

For the single three-dimensional (3D) spheroid-formation assay, cells were allowed to form primary and secondary spheroids as detailed above. At day 14 of secondary spheroid formation, they were dissociated into a single spheroid of the same size and each spheroid was then treated with noncytotoxic concentrations of chrysotoxine
$(0-20 \mu \mathrm{M})$. Phase-contrast images of the secondary spheroids were taken 3 and 7 days after chrysotoxine treatment under a phasecontrast microscope (Olympus IX51 with DP70).

WST Assay. Cells were seeded onto a 24 -well ultralow attachment plate with approximately $2.5 \times 10^{3}$ cells/well using RPMI serum-free medium. The primary spheroids were allowed to form for 7 days. At day 7, primary spheroids were then resuspended into single cells using $1 \mathrm{mM}$ EDTA, and $2.5 \times 10^{3}$ cells/well were reseeded onto a 24 -well ultralow attached plate and cultured for 14 days to form secondary spheroids. At day 14, the CSC-rich population was treated with the noncytotoxic concentration of chrysotoxine for 72 hours and analyzed for cell viability using the WST assay. The harvested cells were incubated with $10 \%$ WST for 2 hours at $37^{\circ} \mathrm{C}$ and the intensity of the formazan product was measured at $450 \mathrm{~nm}$ using a plate reader. Cell viability was calculated from optical density readings and is represented in percentages with respect to the nontreated control value.

Plasmids and Transfection. The Src expression plasmid and control plasmids were purchased from OriGene Technologies Inc. (Rockville, MD). Cells were transfected with the Src expression or control plasmid using Lipofectamine 2000 reagent, according to the manufacturer's protocol (Invitrogen, Carlsbad, CA) in RPMI medium in the absence of serum and antibiotics. After 12 hours of incubation, the medium was replaced with complete culture medium containing $10 \%$ FBS. To obtain stable transfectants, the cells were then selected for G418 $(400 \mu \mathrm{g} / \mathrm{ml})$ resistance for 30 days. Expression of Src was determined by Western blot analysis. The cells were cultured in RPMI 1640 (antibiotic-free) medium for at least two passages before further experiments (Chanvorachote and Luanpitpong, 2016).

Retrovirus Production and Inhibition of Src by RNA Interference. Retrovirus plasmids carrying a short hairpin (sh) RNA sequence against human Src and negative scramble for shRNA were obtained from OriGene Technologies Inc. and shSrc retrovirus production was performed using Platinum-A retroviral packaging cells (American Type Culture Collection). Cells were incubated with shSrc viral particles and negative scramble for shRNA control for 48 hours. Then cells were cultured and selected for puromycin $(1 \mu \mathrm{g} / \mathrm{ml})$ resistance for 30 days. The infected cells were analyzed for Src expression prior to use by Western blotting (Chanvorachote and Luanpitpong, 2016).

Western Blot Analysis. Cells were incubated with lysis buffer containing $20 \mathrm{mM}$ Tris- $\mathrm{HCl}$ ( $\mathrm{pH}$ 7.5), $150 \mathrm{mM} \mathrm{NaCl}, 1 \mathrm{mM} \mathrm{Na}_{3} \mathrm{VO}_{4}, 1 \%$ Triton X-100, $50 \mathrm{mM} \mathrm{NaF}, 100 \mathrm{mM}$ phenylmethylsulfonyl fluoride, $10 \%$ glycerol, and cocktail protease inhibitor mixture (Roche Molecular Biochemicals, Indianapolis, IN) for 45 minutes on ice. The cell lysates were evaluated for protein content using the BCA protein assay kit from Pierce Biotechnology (Rockford, IL). Equal amounts of denatured protein samples $(60 \mu \mathrm{g})$ were loaded onto $10 \%$ SDS-PAGE before they were transferred onto $0.45-\mu \mathrm{m}$ nitrocellulose membranes (Bio-Rad, Hercules, CA). Transferred membranes were blocked for 1 hour in 5\% nonfat dry milk in Tris-buffered saline with Tween 20 (25 mM Tris-HCl, pH 7.5, $125 \mathrm{mM} \mathrm{NaCl}$, and $0.05 \%$ Tween 20 ) and incubated overnight with specific primary antibodies against CD133, CD44, ABCG2, ALDH1A1, total Src, phosphorylated Src (Y416), total Akt, phosphorylated Akt (Ser473), Sox2, Oct4, Nanog, and 3-phosphate dehydrogenase. Membranes were washed three times with Tris-buffered saline with Tween 20 and incubated with appropriate horseradish peroxidase-labeled secondary antibodies for 2 hours at room temperature. The immune complexes were detected

Fig. 4. Chrysotoxine suppresses CSC growth in a CSC-rich population. (A, B, D, and E) H460 (A and B) and H23 (D and E) cell secondary spheroids were dissociated into single spheroids of the same size and treated with a noncytotoxic concentration of chrysotoxine for 3 and 7 days. Phase-contrast images of secondary spheroids at day 0,3 , and 7 for the treated and untreated cells (A and D) and the spheroid size relative to that of the untreated group (B and E). (C and F-H) The cell viability of H460 (C) and H23 (F) cells in a detached condition was determined in the CSC-rich populations after treatment with or without a noncytotoxic concentration of chrysotoxine for 72 hours and was analyzed for cell viability using the WST assay. In addition, the level of apoptotic and necrotic cell death was evaluated at the same time for the $\mathrm{H} 460(\mathrm{G})$ and $\mathrm{H} 23(\mathrm{H})$ cells and is displayed as a percentage relative to the untreated control cells. All plots show the mean \pm S.D. $(n=5) . * P<0.05$ vs. untreated cells. Original magnification, $10 \times$ in (A) and (D). 
A WT

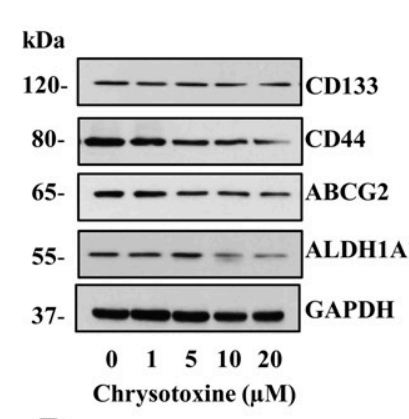

B
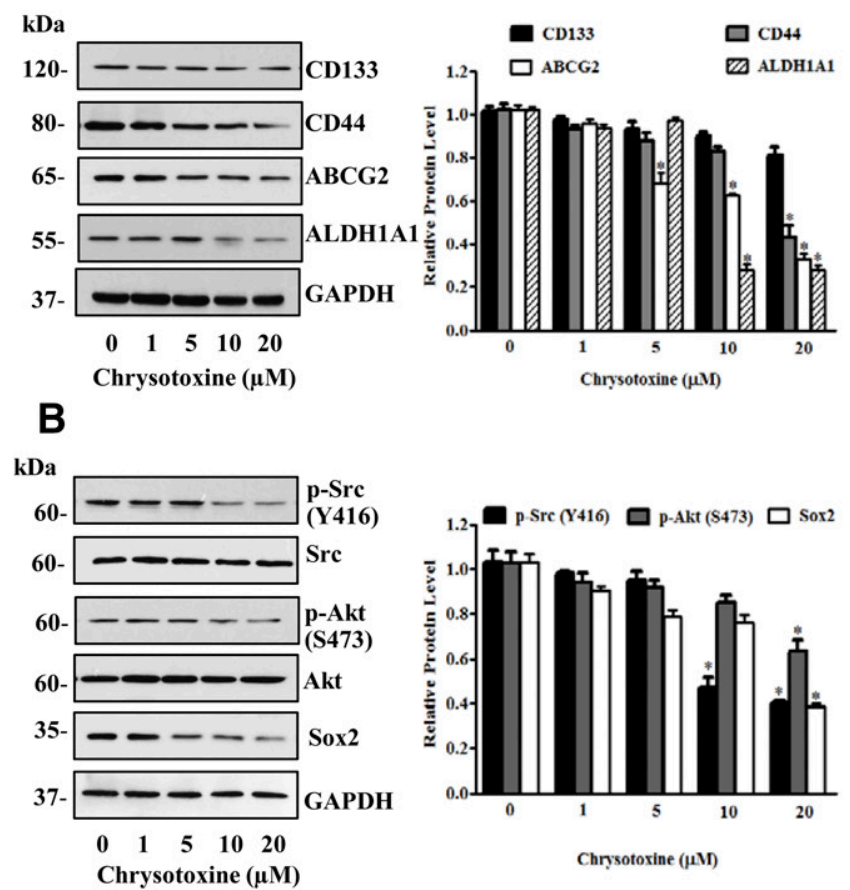

C

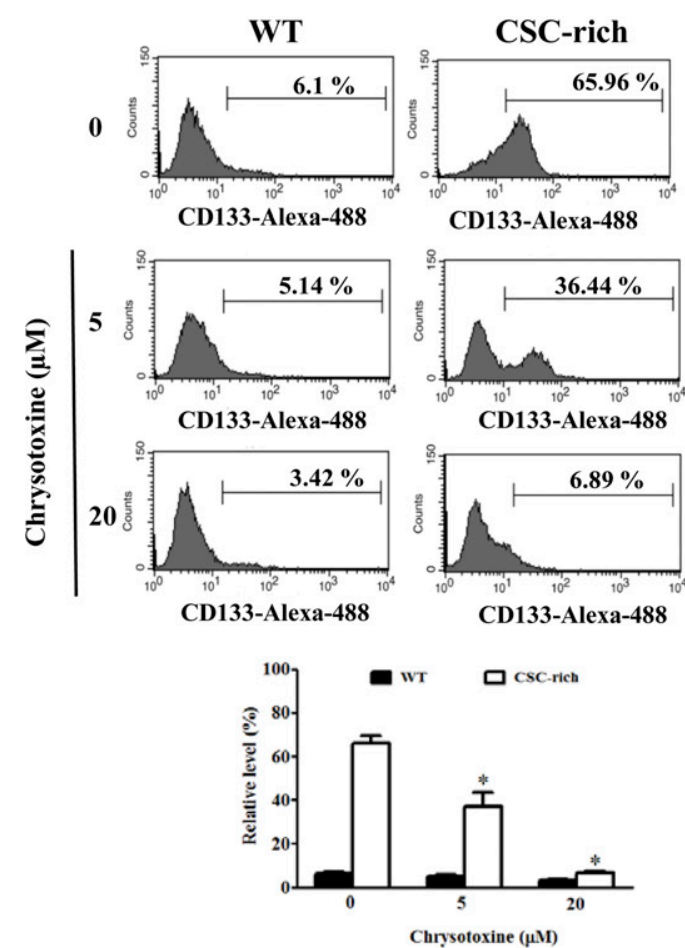

D

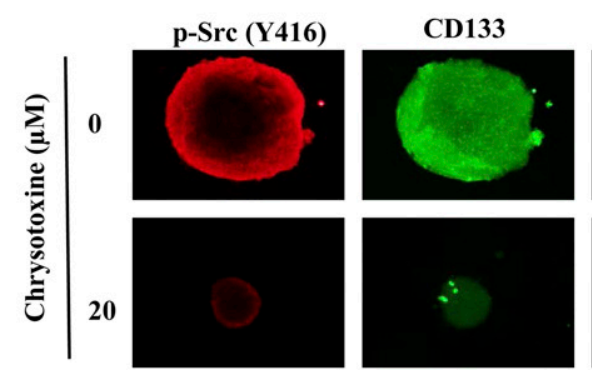

CSC-rich
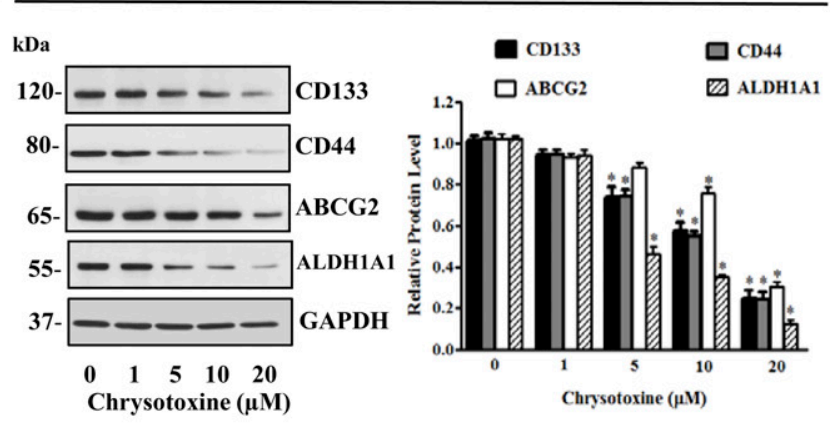
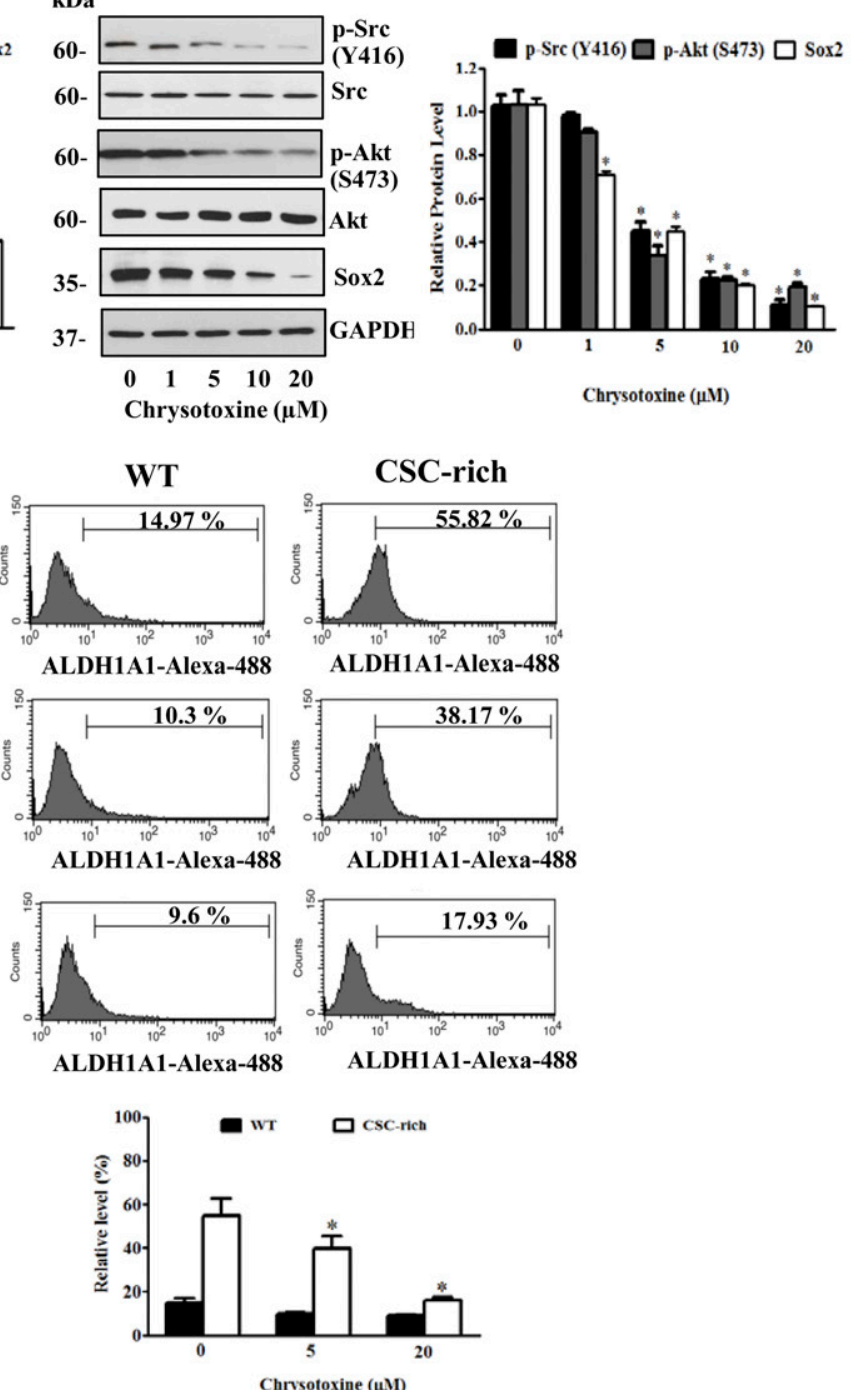

DAPI
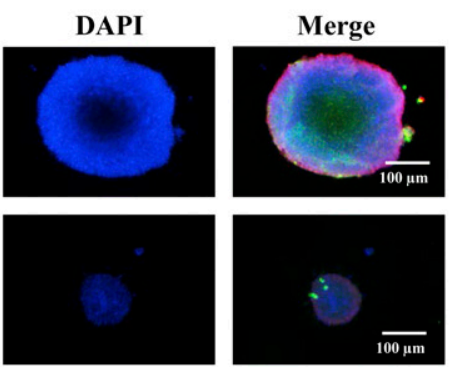
by Super Signal West Pico chemiluminescent substrate (Pierce Biotechnology) and exposed to film.

Flow Cytometry Analysis. Cell pellets were incubated overnight at $4^{\circ} \mathrm{C}$ with rabbit anti-CD133 (Cell Applications) or anti-ALDH1A1 (Cell Signaling Technology) antibody. Cells were washed and incubated for 1 hour with Alexa Fluor 488-conjugated goat anti-rabbit IgG $(\mathrm{H}+\mathrm{L})$ secondary antibody (Life Technologies, Eugene, OR). Fluorescence intensity was determined by flow cytometry using a 488-nm excitation beam and a 519-nm band-pass filter with at least 100,000 cells in each experiment (FACSort; Becton Dickinson, Rutherford, NJ). The mean fluorescence intensity was quantified by CellQuest software (Becton Dickinson).

Immunofluorescence Staining. Cells were allowed to form primary and secondary spheroids as detailed above. At day 14 of secondary spheroid formation, cells were then treated with a noncytotoxic concentration of chrysotoxine $(20 \mu \mathrm{M})$. After treatment, the cells were fixed with $4 \%$ paraformaldehyde for 30 minutes and permeabilized with $0.1 \%$ Triton X-100 for 20 minutes. The cells were then incubated with $3 \%$ bovine serum albumin for 30 minutes, washed, and incubated with anti-p-Src or anti-CD133 antibody overnight at $4^{\circ} \mathrm{C}$. The cells were then washed and incubated with Alexa Fluor 488-conjugated (Invitrogen) goat anti-mouse IgG $(\mathrm{H}+\mathrm{L})$ secondary antibody or Alexa Fluor 594-conjugated (Invitrogen) goat anti-rabbit IgG $(\mathrm{H}+\mathrm{L})$ secondary antibody for 1 hour at room temperature in the dark. The cells were washed with phosphatebuffered saline and costained with $4^{\prime}, 6$-diamidino-2-phenylindole dye and were then visualized and imaged by fluorescence microscopy (Nikon Eclipse Ts2).

Extreme Limiting Dilution Assay. The extreme limiting dilution assay (ELDA) used in this study was slightly modified from previously described methods (Rota et al., 2012; Sarkar et al., 2014; Qureshi-Baig et al., 2016). Cells were plated in gradually decreasing numbers from 200 cells/well to 1 cell/well in $200 \mu \mathrm{l}$ onto a 96 -well ultralow attachment plate and cultured for 14 days, and the number of wells containing spheres for each cell-plating density (number of positive cultures) was then recorded. Spheroid formation with chrysotoxine-treated cells were calculated in all wells compared with the control.

Statistical Analysis. Data are shown as means \pm S.D., derived from at least four independent experiments. Statistical analysis was performed by one-way analysis of variance and Turkey's post hoc test at a significance level of $P<0.05$ level.

\section{Results}

Cytotoxicity of Chrysotoxine on Lung Cancer Cells But Not Normal Epithelial Cells. Chrysotoxine has the ability to attenuate metastasis and sensitize anoikis (Chanvorachote et al., 2013). However, the effect of chrysotoxine on CSC-like phenotypes has not yet been clarified. To test the effect of chrysotoxine on CSC-like phenotypes, its appropriate noncytotoxic concentrations were evaluated. Human NSCLC H460 and H23 cells and normal keratinocytes containing normal stem cells were treated with various concentrations of chrysotoxine $(0,1,5,10,20$, and $50 \mu \mathrm{M})$ for 24 hours and then their cell viability was determined after 24 hours by the MTT viability assay. Chrysotoxine was found to be nontoxic at concentrations of $\leq 20 \mu \mathrm{M}$ in both $\mathrm{H} 460$ and $\mathrm{H} 23$ cells, with no significantly decreased cell viability or increased apoptosis/necrotic cell death, whereas significantly reduced cell viability and an increased level of apoptosis was noted at $50 \mu \mathrm{M}$ (Fig. 2). Interestingly, chrysotoxine showed no cytotoxic effect on the nontumor cell lines at all tested concentrations $(0-50 \mu \mathrm{M})$ (Fig. $2 \mathrm{C}$ ). The derived $\mathrm{IC}_{50}$ values of chrysotoxine were approximately $127.34 \pm 1.65 \mu \mathrm{M}$ for $\mathrm{H} 460$ cells and $145.47 \pm 9.38 \mu \mathrm{M}$ for H23 cells (data not shown). Thus, nontoxic $(\leq 20 \mu \mathrm{M})$ concentrations of chrysotoxine were further tested for their effects on CSC-like phenotypes.

Chrysotoxine Suppresses CSC-Like Phenotypes. The fundamental properties of CSCs are their ability to self-renew and generate differentiated progeny. The capability of tumor cells to form spheroids under the nonattached and serumstarved condition of the tumor sphere formation assay is the gold standard for evaluation of CSCs and their self-renewal (Cao et al., 2011; Pastrana et al., 2011). Accordingly, the ability of chrysotoxine to suppress this activity was determined. $\mathrm{H} 460$ and $\mathrm{H} 23$ cells were treated with noncytotoxic concentrations of chrysotoxine $(0-20 \mu \mathrm{M})$ for 72 hours, and then the cells were subjected to the spheroid-formation assay. The control cells had the ability to form aggregates and spheroids, whereas treatment of the cells with nontoxic concentrations of chrysotoxine dramatically reduced the size of the tumor spheroids in a dose-dependent manner (Fig. 3, A and D), suggesting that chrysotoxine has a suppressing effect on the CSC populations in these cells. In addition, chrysotoxine treatment did not significantly decrease the cell proliferation under these conditions (Fig. 3, C and F).

Having shown the inhibitory effect of chrysotoxine on the CSC population in a total lung cancer cell population, we next confirmed this effect in a 3D CSC-rich population. The CSCrich populations of $\mathrm{H} 460$ and $\mathrm{H} 23$ cells in 3D culture were created as previously described (Cao et al., 2011; Pastrana et al., 2011). All of the $\mathrm{H} 460$ and $\mathrm{H} 23$ cells that were passaged from first-generation tumor spheres preserved the ability to form second-generation spheres. At 14 day of culture, the secondary spheroids were selected into single 3D spheroids of a similar morphology and size and each spheroid was then treated with the noncytotoxic concentrations of chrysotoxine and monitored after 3 and 7 days.

Representative images of the CSC spheroids in the control and chrysotoxine-treated cells at days 0,3 , and 7 are shown in Fig. 4. Treatment of the CSC spheres with chrysotoxine at 5-20 $\mu \mathrm{M}$ significantly reduced the CSC populations in both $\mathrm{H} 460$ and $\mathrm{H} 23$ cells, with a significant decrease in the size of the H460 CSC spheres by approximately $40 \%, 53 \%$, and $67 \%$ at day 3 after treatment with 5,10 , and $20 \mu \mathrm{M}$ chrysotoxine, respectively, compared with the control (Fig. 4B). In addition,

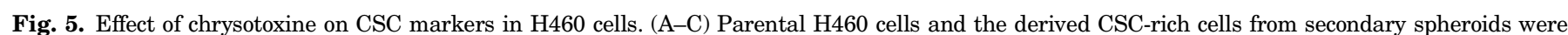

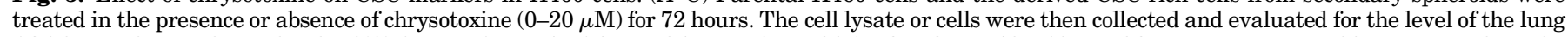

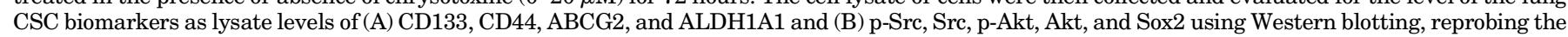

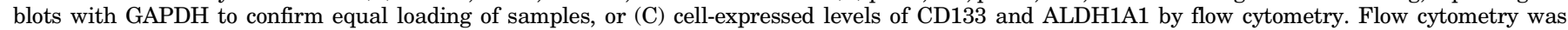

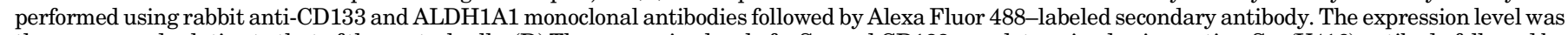

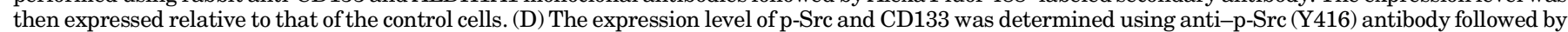

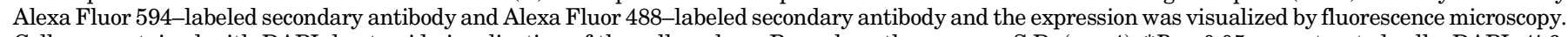

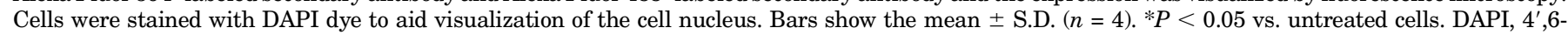
diamidino-2-phenylindole; GAPDH, 3-phosphate dehydrogenase; WT, wild type. Original magnification, $10 \times$ in $(\mathrm{D})$. 
A

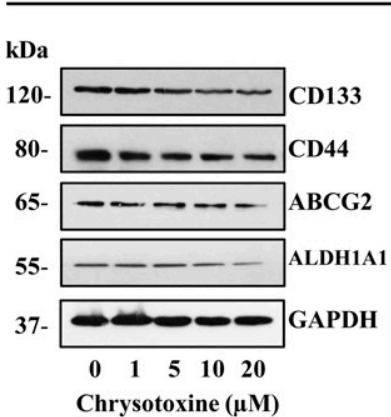

B
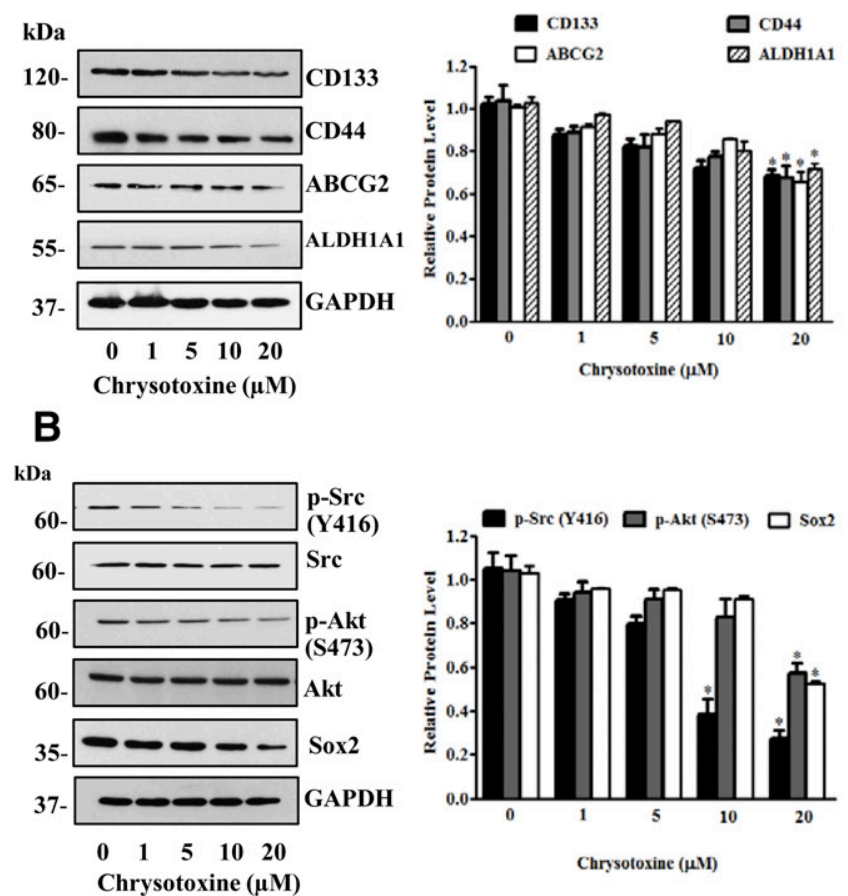

CSC-rich
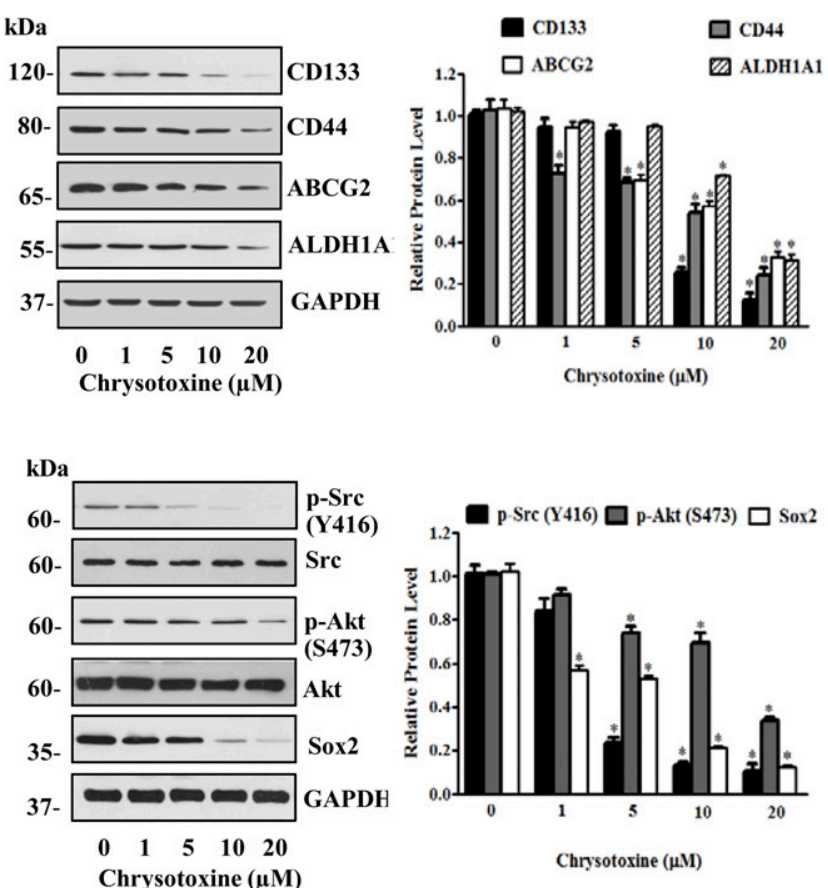

C

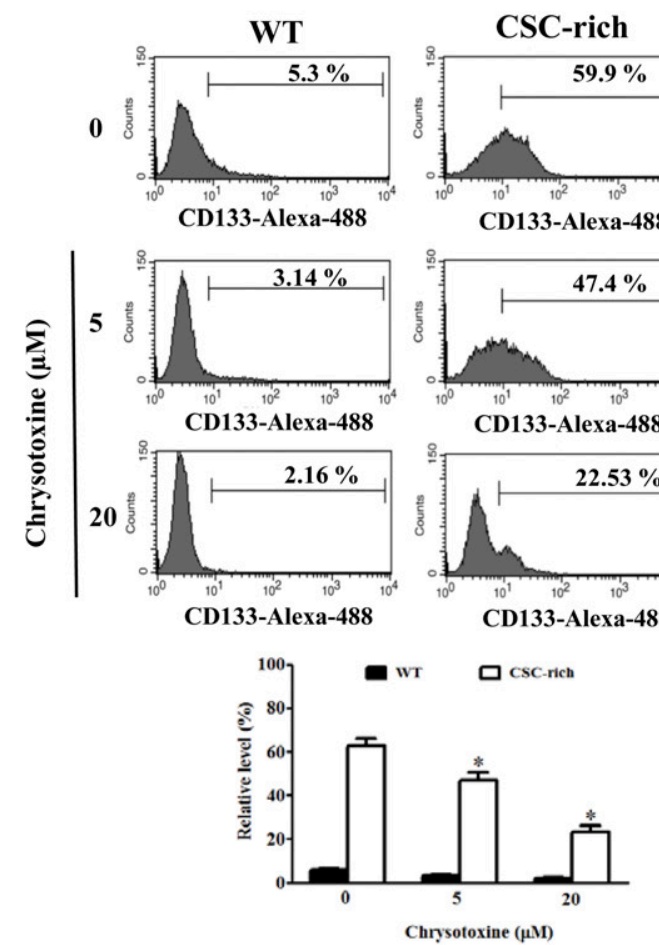

D
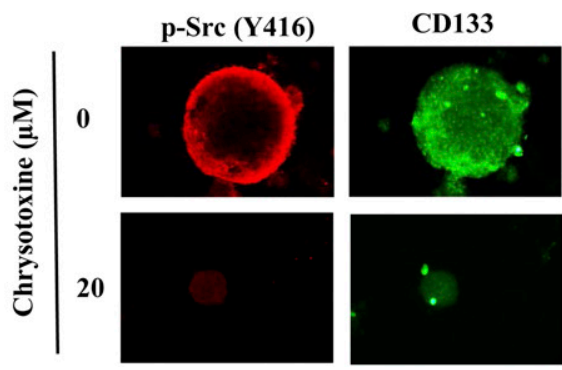

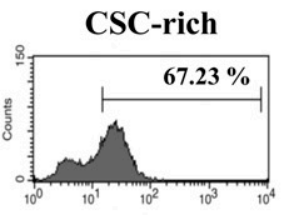

AI.DH1 A1-Alexa-488

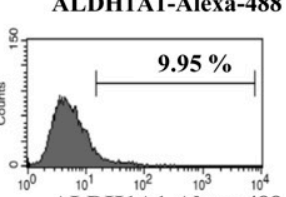

ALDH1A1-Alexa-488
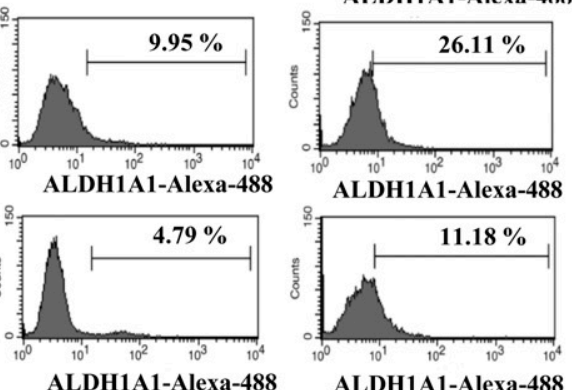

ALDH1A1-Alexa-488

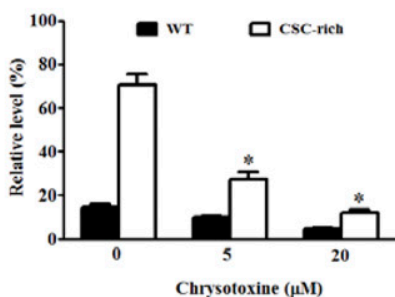

DAPI

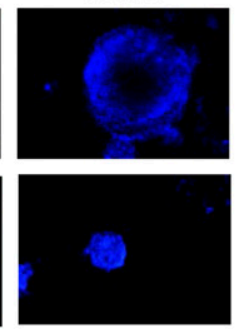

Merge

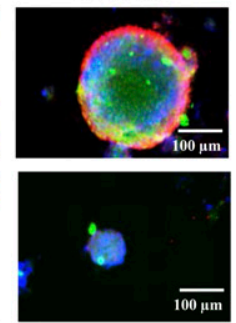


a further decrease in the H460 CSC spheroid size by approximately $30 \%, 60 \%, 90 \%$, and $95 \%$ relative to the control was seen in cells treated with $1,5,10$, and $20 \mu \mathrm{M}$ chrysotoxine, respectively, at day 7 (Fig. $4 \mathrm{~B}$ ).

Similar results were found for the H23 cells, in which treatment of H23 CSC spheres with chrysotoxine resulted in the dramatic shrinkage of spheroids in a dose-dependent manner (Fig. 4E). Significant suppression was first detected in response to $5 \mu \mathrm{M}$ chrysotoxine at day 3, with an approximately $30 \%$ size reduction of the CSC spheres; this decreased in size by approximately $40 \%, 60 \%, 80 \%$, and $92 \%$ relative to the control after treatment with $1,5,10$, and $20 \mu \mathrm{M}$ chrysotoxine, respectively, at day 7 (Fig. $4 \mathrm{E}$ ). In addition, to confirm the effect of chrysotoxine on the viability of CSC, CSC-rich populations of $\mathrm{H} 460$ and $\mathrm{H} 23$ cells were generated as described in the Materials and Methods and the CSC populations were treated with chrysotoxine $(0-20 \mu \mathrm{M})$ for 72 hours prior to determining the cell viability by the WST assay. Chrysotoxine at 5-20 $\mu \mathrm{M}$ significantly decreased the CSC viability in both $\mathrm{H} 460$ and H23 cells (Fig. 4, C and F), whereas chrysotoxine at 10 and $20 \mu \mathrm{M}$ induced a high level of apoptosis in both H460 and H23 CSCs after 72 hours (Fig. 4, G and H).

Given that chrysotoxine caused an apparent decline in CSClike phenotypes (in terms of the spheroid size and cell viability), the effect of chrysotoxine on the CSC biomarkers CD133, CD44, ABCG2, and ALDH1A1 was determined to further confirm the CSC-suppressing effect of chrysotoxine. CSC-rich populations of $\mathrm{H} 460$ and H23 were generated as described in the Materials and Methods and then treated with chrysotoxine (0-20 $\mu \mathrm{M})$ for 72 hours. The expression levels of CD133, CD44, ABCG2, and ALDH1A1 were evaluated by Western blot analysis. Chrysotoxine significantly decreased the cellular levels of CD133, CD44, ABCG2, and ALDH1A1 in both H460 and H23 cells (Figs. 4A and 5A). Significant suppression was first detected with $5 \mu \mathrm{M}$ chrysotoxine and was dose dependent, decreasing by more than $70 \%$ at $20 \mu \mathrm{M}$ chrysotoxine.

Interestingly, chrysotoxine significantly decreased the expression level of CD133, CD44, ABCG2, and ALDH1A1 in the H460 and H23 CSC-rich populations compared with their respective parental cells (Figs. 5A and 6A). Flow cytometry analysis confirmed that the expression of CD133 and ALDH1A1 was strongly increased in the control CSC-rich population (Figs. 5C and 6C) and was significantly decreased by chrysotoxine in a dose-dependent manner to more than an $85 \%$ reduced expression level in the CSC-rich population of both $\mathrm{H} 460$ and $\mathrm{H} 23$ cells at $20 \mu \mathrm{M}$ chrysotoxine. Taken together, a clear CSC-suppressive effect of chrysotoxine in these lung cancer cells was established.

Chrysotoxine Suppresses Sox2 through a Src-Akt Mechanism. Sox2 was recently shown to be involved in the maintenance of CSC characteristics (Boumahdi et al., 2014; Lundberg et al., 2016), in which Sox2 is regulated via the Src pathway (Singh et al., 2012; Tian et al., 2014; Yang et al., 2014). To determine the underlying mechanism of chrysotoxinemediated suppression of CSC-like phenotypes, both H460 and H23 cells and their derived CSC-rich spheroids were treated with chrysotoxine $(0-20 \mu \mathrm{M})$ for 72 hours and the expression levels of p-Src, Src, p-Akt, Akt, and Sox2 were determined by Western blot analysis. Compared with the control cells, chrysotoxine caused a significant decrease in the level of p-Src and p-Akt in a dose-dependent manner (Figs. 5B and 6B), whereas the levels of total Src and Akt were not altered. In addition, the downstream stem cell transcription factor Sox 2 was significantly reduced after the decline in the level of p-Src in both $\mathrm{H} 460$ and H23 cells. Nontoxic concentrations of chrysotoxine significantly decreased the expression level of p-Src, p-Akt, and Sox2 in the CSC-enriched cells, but to a greater level than in their respective parental cells. To confirm, the cells were similarly treated with the chrysotoxine and the expression of p-Src and CD133 in 3D CSC spheroids was determined by immunocytochemistry. Results showed that chrysotoxine-treated cells exhibited decrease in cellular level of p-Src and CD133 with reduced spheroid size (Figs. 5D and 6D). These results suggested that chrysotoxine decreased the stem cell machinery in lung cancer cells, at least in part, by suppressing transcription factor Sox2 through a Src-Akt pathway.

To further confirm the predominant role and mechanism of Src in lung CSC-like phenotype regulation, the Src signal in these cells was suppressed using RNA interference against Src (shSrc) and control shRNA particles. In addition, for contrast, H460 and H23 cells were stably transfected with a Src-overexpressing plasmid to augment the natural Src signal. Both cells were also transfected with the scramble plasmid, and the effects of Src, shRNA, scramble, and control transfections were confirmed by Western blot assay (Supplemental Fig. 1). The shSrc transfected cells exhibited a significantly decreased level of both Src and p-Src, whereas the Src overexpression transfectants showed overexpressed Src and p-Src levels, as expected (Fig. 7, A and D). Western blot analysis of these transfectants for Akt signal detection, Sox2, and CSC markers was then performed as well as the CSC spheroid-formation assay. The existence of lung CSC-like phenotypes in the $\mathrm{H} 460$ and $\mathrm{H} 23$ cell lines and the acquisition and maintenance of lung CSCs was evident. The Srcoverexpressing cells had the greatest ability to form secondary tumor spheres, compared with the CSC populations. In contrast, the Src knockdown cells failed to form and maintain secondary spheroids in both the H460 and H23 cells (Fig. 7, B and E).

For the CSC markers and Akt signaling, the p-Akt and Sox2 expression levels were tightly correlated with the p-Src (Y416)

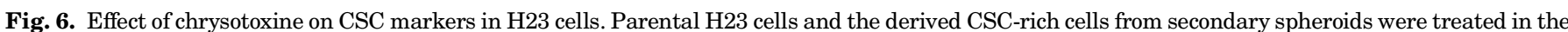

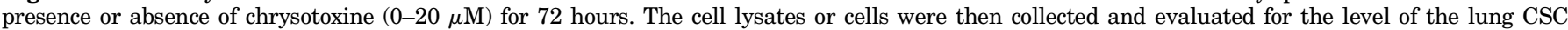

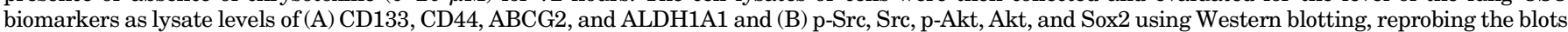

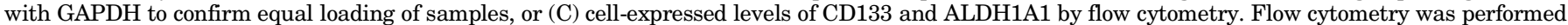

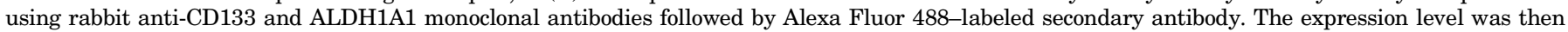

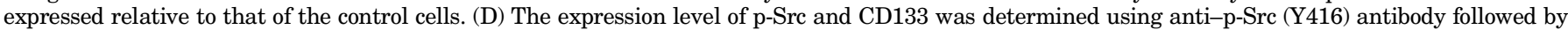

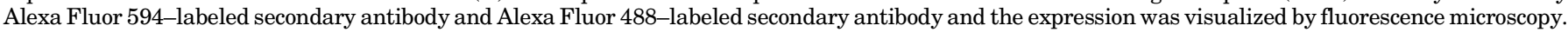

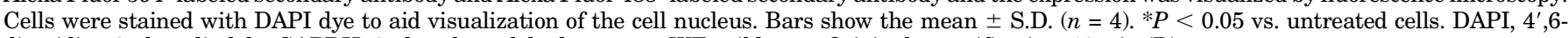
diamidino-2-phenylindole; GAPDH, 3-phosphate dehydrogenase; WT, wild type. Original magnification, 10× in (D).
} 

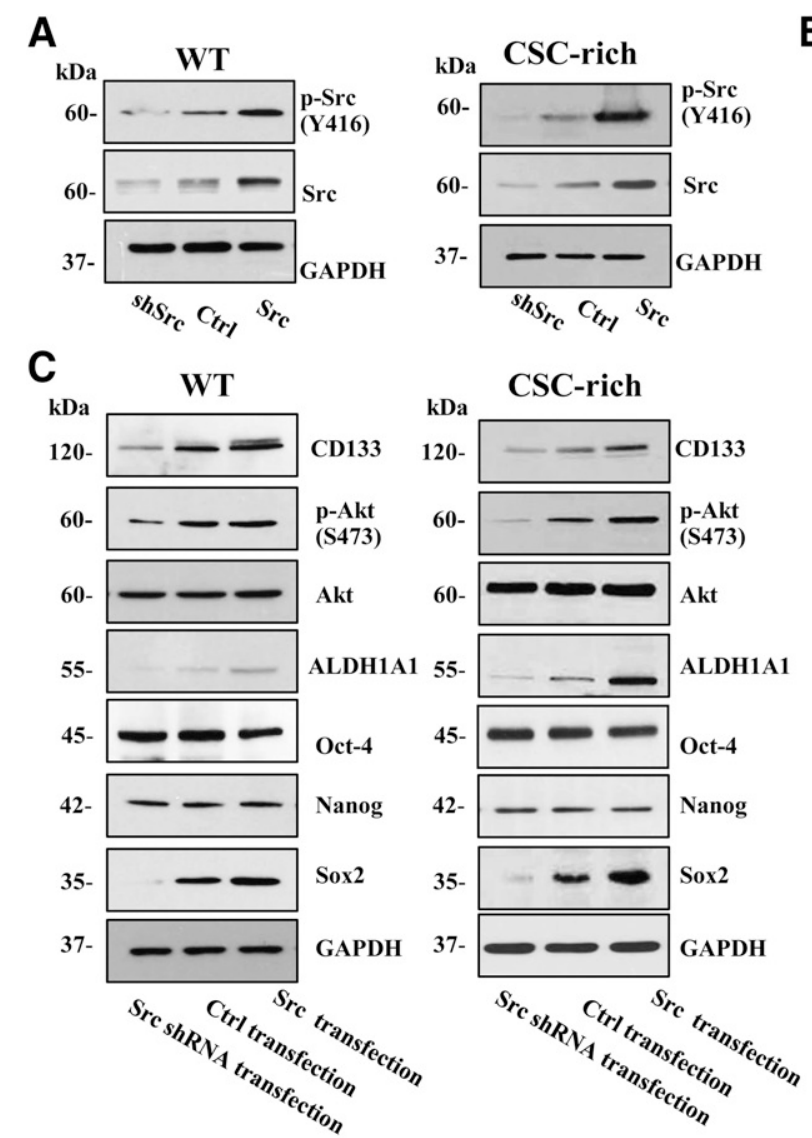

D
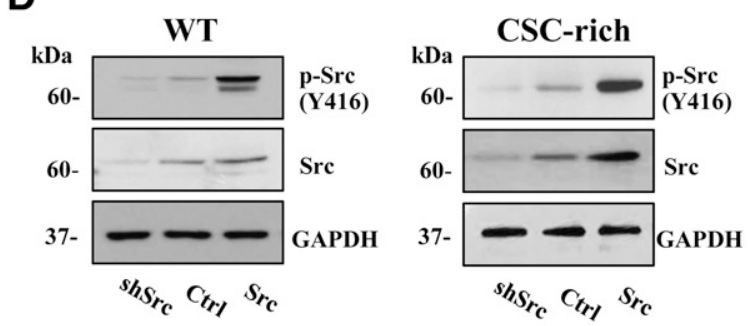

F

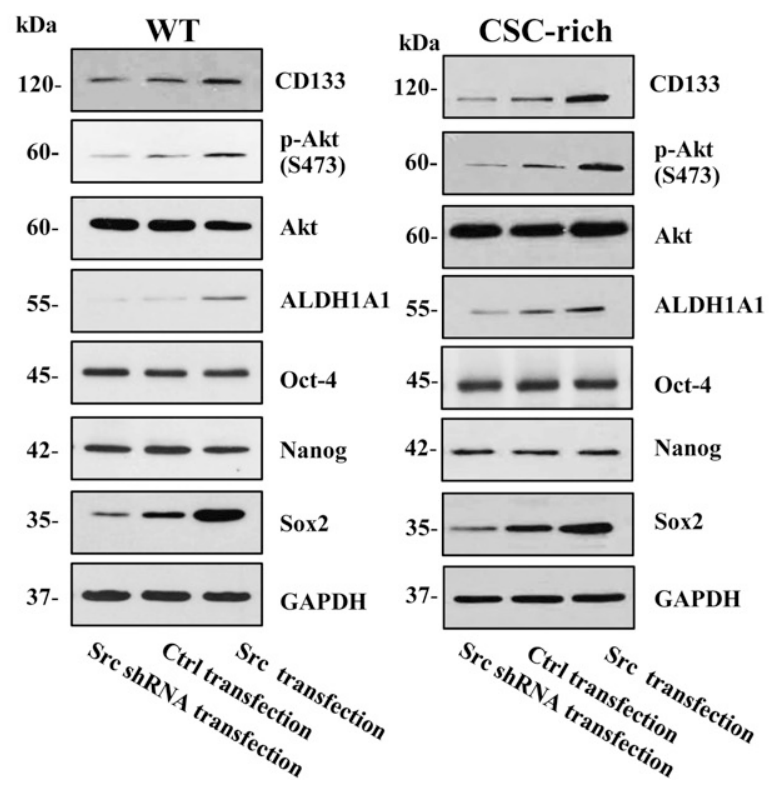

B
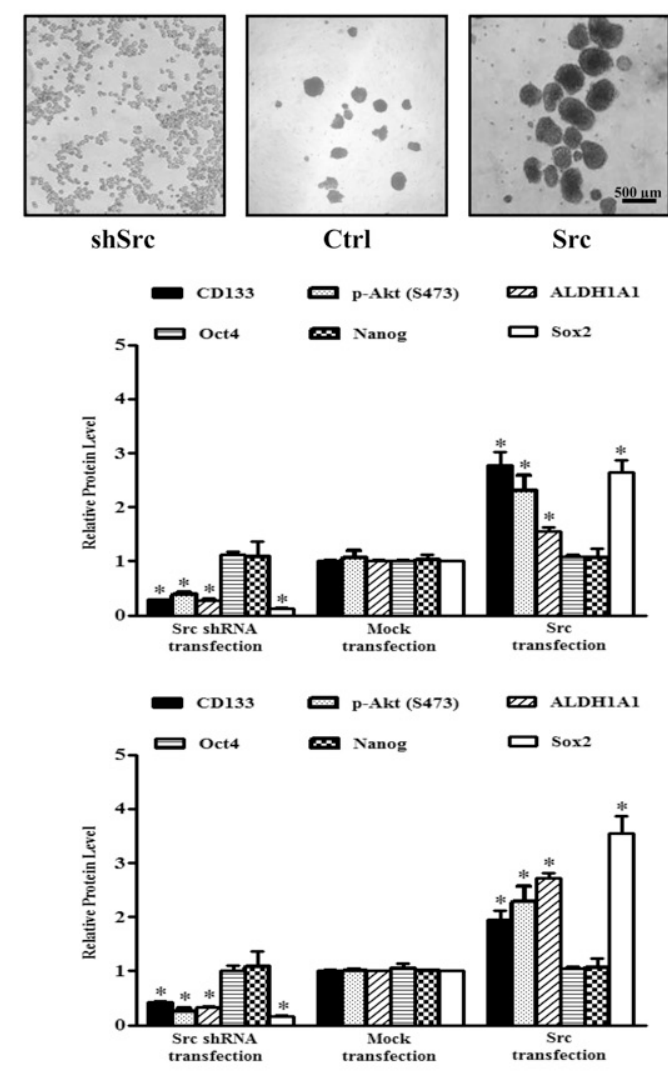

E
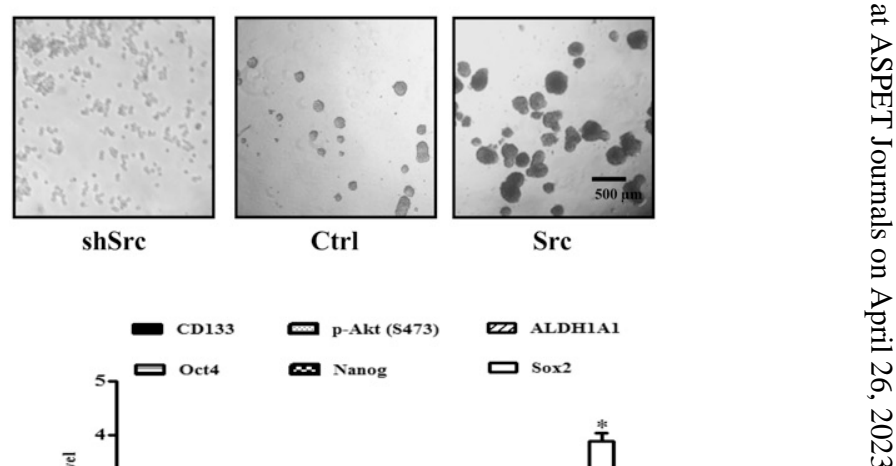
expression. In addition, the expression level of the CSC markers CD133 and ALDH1A1 was found to be correlated with the p-Src level in the Src-overexpressing and Src knockdown cells. However, the expression of Oct4 and Nanog was only slightly altered. Altogether, these results demonstrated that lung CSC-like phenotypes were mediated by p-Src (Y416) through a mechanism involving Akt and Sox2 regulation (Fig. 7, C and F).

Because Sox2 expression and function in the regulation of self-renewal in lung cancer cells has been previously shown to be regulated through the Src-Akt pathway (Singh et al., 2012), we further confirmed such effects of Src signaling in our system using dasatinib, a highly selective Src inhibitor. The effect of chrysotoxine compared with dasatinib treatment was also evaluated. The CSC-rich spheroids of $\mathrm{H} 460$ and H23 cells were treated with noncytotoxic concentrations of dasatinib (200 $\mathrm{nM})$ or chrysotoxine $(20 \mu \mathrm{M})$ for 72 hours, and the expression level of the CSC-regulating proteins was analyzed by Western blot analysis. Results indicated that treatment of the CSC-rich cells with dasatinib as well as chrysotoxine caused a significant decrease in the CSC markers CD133, CD44, ABCG2, and ALDH1A1 (Fig. 8, A and D) compared with the untreated control cells. In addition, treatment of the cells with chrysotoxine and dasatinib significantly reduced the level of p-Src without any change in the level of total Src (Fig. 8, B and E). Importantly, the downstream transcription factors, including p-Akt and Sox2, were decreased, presumably as a consequence of the reduced p-Src level (Dogan et al., 2014). Both $\mathrm{H} 460$ and $\mathrm{H} 23$ cells had the ability to form secondary tumor spheres, revealing the presence of CSC-like phenotype populations. In contrast, dasatinib- and chrysotoxinetreated H460 and $\mathrm{H} 23$ cells failed to form and maintain secondary spheroids (Fig. 8, C and F). Moreover, an ELDA was performed to examine the effect of chrysotoxine. Results indicated that although the nontreated control cells exhibited the ability to form tumor spheres, the H460 and H23 cells treated with chrysotoxine failed to generate spheres (Fig. 8G). To confirm, we have elucidated the CSC-like phenotype suppressive effect of chrysotoxine in enriched primary cancer non-small cells. Consistently, chrysotoxine significantly reduced the ability of the cells to form spheroid (Fig. $8 \mathrm{H}$ ).

Taken together, these results demonstrate that the CSClike phenotypes in these lung cancer cells were mediated through a Src-Akt-Sox2-dependent mechanism and chrysotoxine decreased the stemness of lung cancer cells, at least in part, by suppressing the Src-Akt activating mechanism.

\section{Discussion}

Among human cancers, lung cancer is a leading cause of death due to its high and rapid rate of metastasis, spreading the cancer cells to other parts of the body. The presence of CSCs is potentially an important reason for the resistance and recurrence of cancer after therapy. Therefore, CSCs have continuously gained increasing attention in cancer research (Buettner et al., 2008; Peters et al., 2012; Singh et al., 2012).

It has been proposed that CSCs are the key driving force in tumorigenesis, drug resistance, and metastasis (Dalerba et al., 2007; Medema, 2013). In addition, the majority of current anticancer chemotherapies, while targeting the bulk tumor cells, ultimately fail to achieve efficient clinical outcomes because CSCs show only a limited response to such treatments. Thereafter, attempts have been made to identify potential compounds that are effective against CSCs.

Many researchers have focused on compounds that can suppress CSC-related pathways. The activation of Src, a well known survival and proliferating signal, has been shown to play an important role in regulating stemness in many cell models (Singh et al., 2012). Src (a nonreceptor tyrosine kinase) possesses the ability to mediate cell transformation, including uncontrolled cell division, and activates many downstream targets such as the phosphoinositide 3-kinase/AKT, Ras/mitogen-activated protein kinase, and signal transducer and activator of transcription 3 pathways (Summy and Gallick, 2003; Zhang et al., 2007; Kim et al., 2009). Previous studies revealed that overexpression of Src significantly increased cancer stemness via inducing a self-renewal ability and stabilizing the expression of stemness genes (Zhang et al., 2007; Kim et al., 2009; Picon-Ruiz et al., 2016). In addition, the activation of Src via its phosphorylation at Y416 was shown to lead to the activation of Akt (by phosphorylation at Ser473), which is an important mediator for cell survival and proliferation (Hu et al., 2010). Indeed, Src-Akt was found to be linked with cancer stemness, and inhibition of Src reduced p-Akt and decreased tumor sphere formation (Chen et al., 2001; Koga et al., 2006; Singh et al., 2012). Moreover, Akt is an important mediator that regulates Sox2, which is shown to enhance malignancy through the induction of CSCs. The function of Sox2 involves the self-renewal property of CSCs. Sox2 is a novel target of Src-Akt signaling in NSCLCs that modulates self-renewal and increases CSC-like phenotypes. Taken together, Src-Akt-Sox2 cellular signals may be potential molecular targets for suppressing CSC-like phenotypes (Xiang et al., 2011; Chen et al., 2012, 2013; Chou et al., 2013; Bora-Singhal et al., 2015).

This study demonstrated for the first time that chrysotoxine, a pure compound isolated from $D$. pulchellum, exhibited in vitro CSC-like phenotype-suppressing activity in human NSCLC cells. A previous report demonstrated that chrysotoxine also counteracted $\mathrm{NF}-\kappa \mathrm{B}$ activation by blocking its translocation to the nucleus and thereby prevented the upregulation of inducible nitric oxide synthase and intracellular nitric oxide release (Song et al., 2012). CSCs are regulated by several signaling pathways, including NF- $\kappa \mathrm{B}$, which is responsible for primary tumor formation, drives metastasis, and contributes to resistance to radiation and chemotherapy (Jiang et al., 2014). Furthermore, connections between the NF- $\kappa$ B pathway and oncogenesis in CSCs have

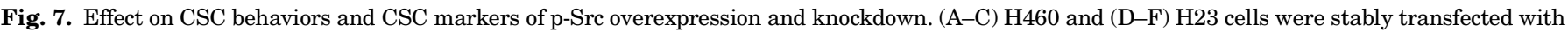

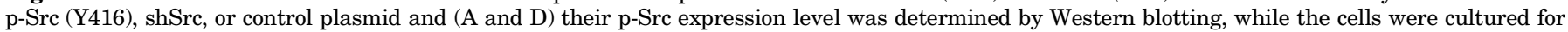

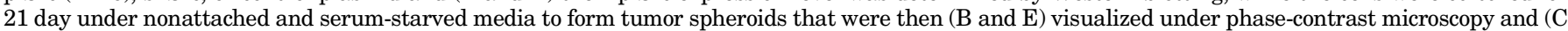

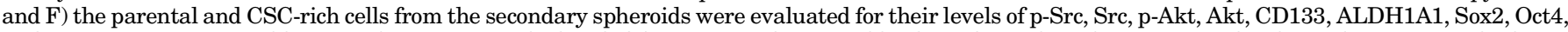

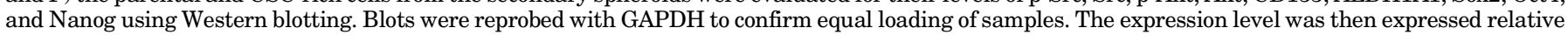
to that of the control cells. Bars are the mean \pm S.D. $(n=4)$. ${ }^{*} P<0.05$ vs. untreated cells. GAPDH, 3 -phosphate dehydrogenase; WT, wild type. 
A

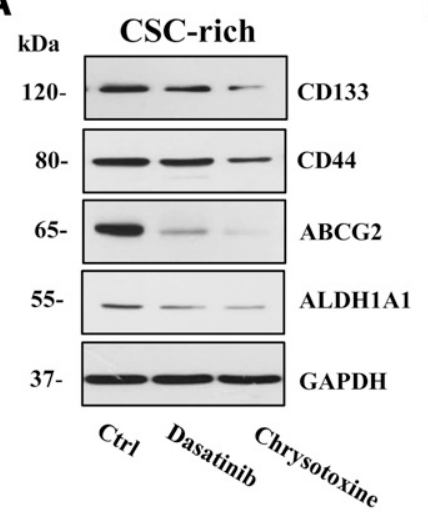

D

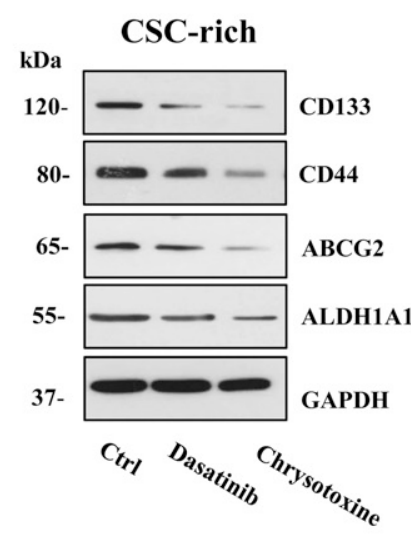

B

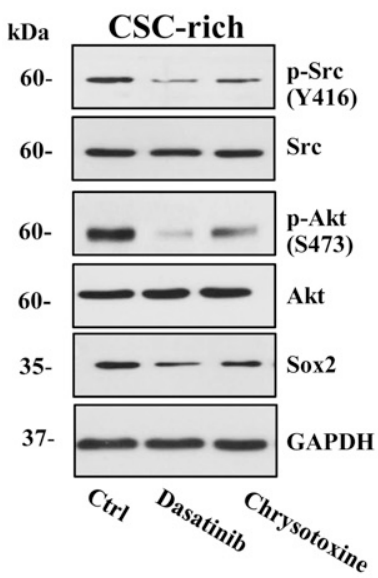

E

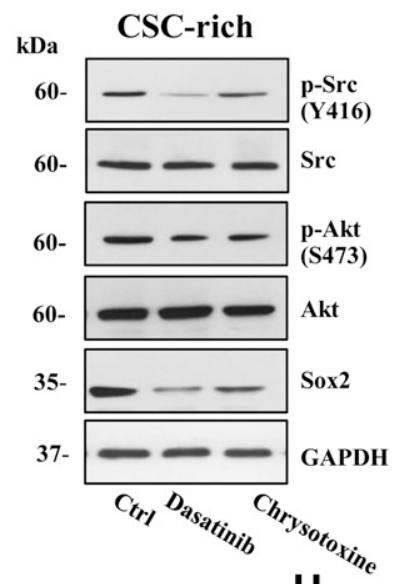

C
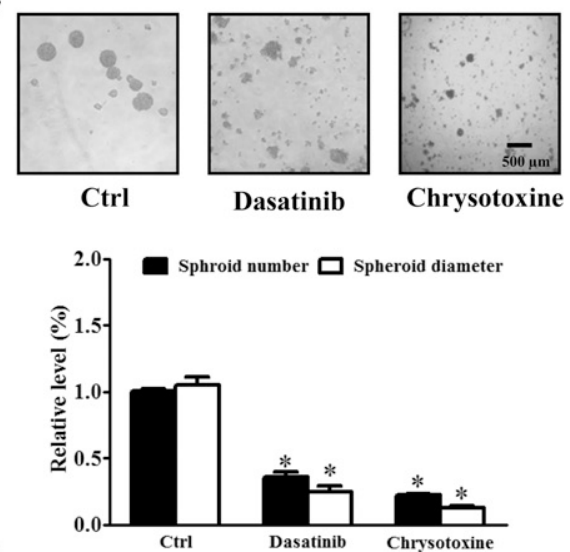

F
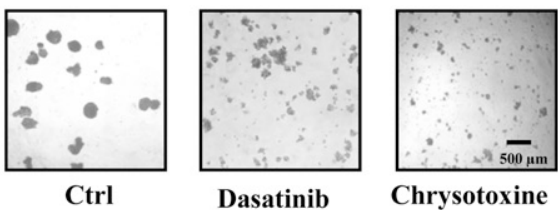

Chrysotoxine

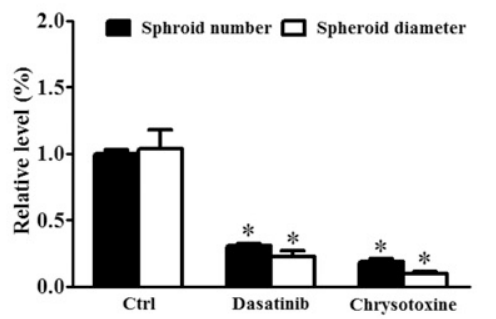

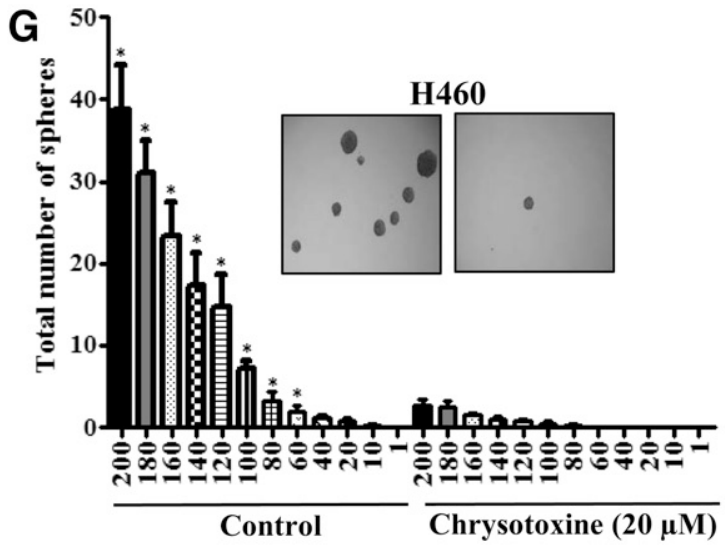

H

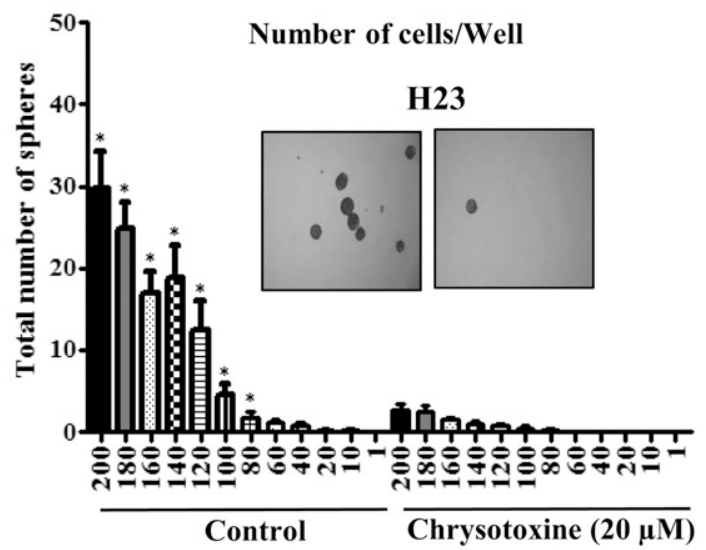

Chrysotoxine (20 $\mu \mathrm{M})$

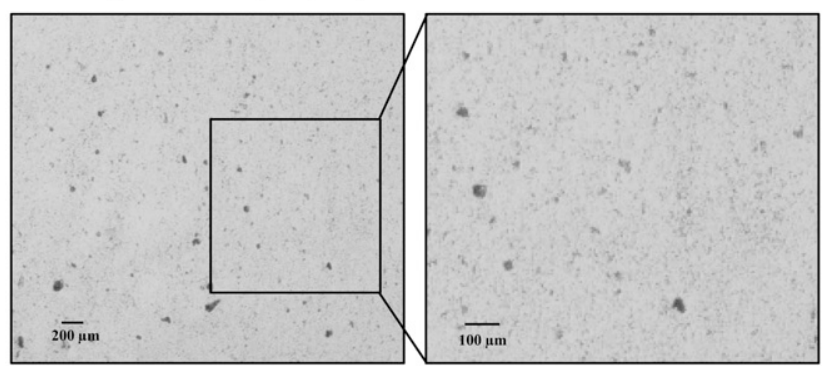

Number of cells/Well 
been described, in which the suppression of its activity contributed to attenuate self-renewal and xenograft tumor growth (Jiang et al., 2014; Vazquez-Santillan et al., 2015; Rinkenbaugh and Baldwin, 2016). In this study, we also described the potential effect of chrysotoxine and showed that the levels of CSC-rich populations of $\mathrm{H} 460$ and $\mathrm{H} 23$ cells in 3D culture were strongly diminished after the treatment (Fig. 4), and CD133, CD44, ABCG2, and ALDH1A1 (stem cell markers in lung cancer) were significantly decreased (Figs. 5 and 6). Recently, pluripotency transcription factor Sox2 was shown to be involved in the maintenance of stem cell characteristics (Lundberg et al., 2016). Sox2 is regulated via Src-Akt activity (Singh et al., 2012; Tian et al., 2014; Yang et al., 2014). In this study, chrysotoxine treatment caused a significant reduction in the level of p-Src and p-Akt in a dose-dependent manner, whereas the total Src and Akt expression levels were not affected, supporting a post-translational (phosphorylation/dephosphorylation) control. In addition, the downstream stem cell transcription factor Sox2 was significantly reduced after the decline in p-Src levels in both $\mathrm{H} 460$ and H23 cells. These results suggest that chrysotoxine treatment decreased the CSC-like phenotypes in lung cancer cells, at least in part, by suppressing transcription factor Sox2 through the Src-Akt pathway (Fig. 7).

Dasatinib has previously been reported to block Src phosphorylation without affecting cell proliferation and survival rates (Buettner et al., 2008; Timeus et al., 2008). To confirm the effect of Src in regulating Sox2 and cancer stem cell markers in our system, the specific Src kinase inhibitor dasatinib was used (Buettner et al., 2008; Timeus et al., 2008; Singh et al., 2012). In this study, compared with dasatinib-treated cells, chrysotoxine also caused a gradual decrease in the expression level of CSC markers CD133, CD44, ABCG2, and ALDH1A1 and significantly reduced the level of p-Src without any change in the total Src level (Fig. 8). Critically, the expression level of downstream transcription factor, Sox2 were decreased, presumably as a consequence of the decreased level of p-Src (Dogan et al., 2014). Taken together, these results demonstrated that the CSC-like phenotypes in these lung cancer cells were mediated through a Src-Akt-Sox2-dependent mechanism and that chrysotoxine decreased the stemness of lung cancer cells.

\section{Conclusion}

In summary, this report provides evidence that chrysotoxine has a potential CSC-suppressing effect in human lung cancer cells. The mechanism by which chrysotoxine decreases stemness likely involves the following steps. Chrysotoxine reduces the active level of Src [p-Src (Y416)], which is required for the subsequent activation of Akt, because the inhibition of Src by Src inhibitor and RNA interference (shRNA) against
Src prevented the formation of p-Akt. The downstream primary target of the Src/Akt signal is the pluripotency transcription factor Sox2. As a consequence of the decreased stem cell regulatory proteins, chrysotoxine induced the downregulation of CSC markers CD133, CD44, ABCG2, and ALDH1, as well as the ability to form and maintain 3D spheres. Because CSCs have been tightly linked to the aggressiveness of cancers, these findings could be beneficial to the development of this compound as a novel therapy for CSC therapeutic approaches.

\section{Authorship Contributions}

Participated in research design: Pongrakhananon, Chanvorachote. Conducted experiments: Bhummaphan, Chanvorachote.

Performed data analysis: Bhummaphan, Chanvorachote, Sritularak. Wrote or contributed to the writing of the manuscript: Bhummaphan, Pongrakhananon, Sritularak, Chanvorachote.

\section{References}

Bao B, Ahmad A, Azmi AS, Ali S, and Sarkar FH (2013) Overview of cancer stem cells (CSCs) and mechanisms of their regulation: implications for cancer therapy. Curr Protoc Pharmacol Chapter 14:Unit 14.25

Bora-Singhal N, Perumal D, Nguyen J, and Chellappan S (2015) Gli1-mediated regulation of Sox2 facilitates self-renewal of stem-like cells and confers resistance to EGFR inhibitors in non-small cell lung cancer. Neoplasia 17:538-551.

Boumahdi S, Driessens G, Lapouge G, Rorive S, Nassar D, Le Mercier M, Delatte B, Caauwe A, Lenglez S, Nkusi E, et al. (2014) SOX2 controls tumour initiation and cancer stem-cell functions in squamous-cell carcinoma. Nature 511:246-250.

Buettner R, Mesa T, Vultur A, Lee F, and Jove R (2008) Inhibition of Src family kinases with dasatinib blocks migration and invasion of human melanoma cells. Mol Cancer Res 6:1766-1774.

Cao L, Zhou Y, Zhai B, Liao J, Xu W, Zhang R, Li J, Zhang Y, Chen L, Qian H, et al. (2011) Sphere-forming cell subpopulations with cancer stem cell properties in human hepatoma cell lines. BMC Gastroenterol 11:71.

Chanvorachote P, Kowitdamrong A, Ruanghirun T, Sritularak B, Mungmee C, and Likhitwitayawuid K (2013) Anti-metastatic activities of bibenzyls from Dendrobium pulchellum. Nat Prod Commun 8:115-118.

Chanvorachote P and Luanpitpong S (2016) Iron induces cancer stem cells and aggressive phenotypes in human lung cancer cells. Am J Physiol Cell Physiol 310: C728-C739.

Chen R, Kim O, Yang J, Sato K, Eisenmann KM, McCarthy J, Chen H, and Qiu Y (2001) Regulation of Akt/PKB activation by tyrosine phosphorylation. J Biol Chem 276:31858-31862.

Chen S, Xu Y, Chen Y, Li X, Mou W, Wang L, Liu Y, Reisfeld RA, Xiang R, Lv D, et al. (2012) SOX2 gene regulates the transcriptional network of oncogenes and affects tumorigenesis of human lung cancer cells. PLoS One 7:e36326.

Chen Y, Huang Y, Huang Y, Chen J, Wang S, and Zhou J (2013) The prognostic value of SOX2 expression in non-small cell lung cancer: a meta-analysis. PLoS One 8: e71140.

Chou YT, Lee CC, Hsiao SH, Lin SE, Lin SC, Chung CH, Chung CH, Kao YR, Wang $\mathrm{YH}$, Chen CT, et al. (2013) The emerging role of SOX2 in cell proliferation and survival and its crosstalk with oncogenic signaling in lung cancer. Stem Cells 31: 2607-2619.

Condello S, Morgan CA, Nagdas S, Cao L, Turek J, Hurley TD, and Matei D (2015) $\beta$-Catenin-regulated ALDH1A1 is a target in ovarian cancer spheroids. Oncogene 34:2297-2308.

Dalerba P, Cho RW, and Clarke MF (2007) Cancer stem cells: models and concepts. Annu Rev Med 58:267-284.

Dogan I, Kawabata S, Bergbower E, Gills JJ, Ekmekci A, Wilson W, 3rd, Rudin CM, and Dennis PA (2014) SOX2 expression is an early event in a murine model of EGFR mutant lung cancer and promotes proliferation of a subset of EGFR mutant lung adenocarcinoma cell lines. Lung Cancer 85:1-6.

Grun D, Adhikary G, and Eckert RL (2016) VEGF-A acts via neuropilin-1 to enhance epidermal cancer stem cell survival and formation of aggressive and highly vascularized tumors. Oncogene 35:4379-4387.

Hu Q, Zhang L, Wen J, Wang S, Li M, Feng R, Yang X, and Li L (2010) The EGF receptor-sox2-EGF receptor feedback loop positively regulates the self-renewal of neural precursor cells. Stem Cells 28:279-286.

Fig. 8. The effect of dasatinib and chrysotoxine on CSC markers. (A-F) The CSC-rich cells from secondary spheroids of H460 (A-C) and H23 (D-F) were separately treated with noncytotoxic concentrations of dasatinib $(200 \mathrm{nM})$ or chrysotoxine $(20 \mu \mathrm{M})$ for 72 hours or left untreated as the control group. The spheroids were collected and the cellular lysate levels of (A and D) CD133, CD44, ABCG2, and ALDH1A1 and (B and E) p-Src, Src, p-Akt, Akt, and Sox2 were analyzed by Western blotting. Blots were reprobed with GAPDH to confirm equal loading of samples. (C and F) In addition, the treated secondary spheroids were visualized under phase-contrast microscopy. (G) H460 and H23 cells were plated in decreasing numbers from 200 cells/well to 1 cell/well in $200 \mu \mathrm{l}$ RPMI and cultured for 14 days, and the number of wells containing spheres for each cell was then calculated. (H) An enriched primary NSCLC stem cell was treated with $20 \mu \mathrm{M}$ chrysotoxine, and the spheroid size and spheroid number were visualized under phase-contrast microscopy compared with untreated control cells. Bars are the mean \pm S.D. $(n=4)$. $P<0.05$ vs. untreated cells. Ctrl, control; GAPDH, 3-phosphate dehydrogenase. 
Jeong J-Y, Kang H, Kim TH, Kim G, Heo J-H, Kwon A-Y, Kim S, Jung SG, and An HJ (2017) MicroRNA-136 inhibits cancer stem cell activity and enhances the antitumor effect of paclitaxel against chemoresistant ovarian cancer cells by targeting Notch3. Cancer Lett 386:168-178.

Jiang R, Li Y, Zhang A, Wang B, Xu Y, Xu W, Zhao Y, Luo F, and Liu Q (2014) The acquisition of cancer stem cell-like properties and neoplastic transformation of human keratinocytes induced by arsenite involves epigenetic silencing of let-7c via Ras/NF-кB. Toxicol Lett 227:91-98.

Kantara C, O'Connell M, Sarkar S, Moya S, Ullrich R, and Singh P (2014) Curcumin promotes autophagic survival of a subset of colon cancer stem cells, which are ablated by DCLK1-siRNA. Cancer Res 74:2487-2498.

Kim LC, Song L, and Haura EB (2009) Src kinases as therapeutic targets for cancer. Nat Rev Clin Oncol 6:587-595.

Koga F, Xu W, Karpova TS, McNally JG, Baron R, and Neckers L (2006) Hsp90 inhibition transiently activates Src kinase and promotes Src-dependent Akt and Erk activation. Proc Natl Acad Sci USA 103:11318-11322.

Levina V, Marrangoni AM, DeMarco R, Gorelik E, and Lokshin AE (2008) Drugselected human lung cancer stem cells: cytokine network, tumorigenic and metastatic properties. PLoS One 3:e3077.

Lundberg IV, Edin S, Eklöf V, Öberg Å, Palmqvist R, and Wikberg ML (2016) SOX2 expression is associated with a cancer stem cell state and down-regulation of CDX2 in colorectal cancer. BMC Cancer 16:471.

Medema JP (2013) Cancer stem cells: the challenges ahead. Nat Cell Biol 15:338-344.

Moselhy J, Srinivasan S, Ankem MK, and Damodaran C (2015) Natural products that target cancer stem cells. Anticancer Res 35:5773-5788.

Pastrana E, Silva-Vargas V, and Doetsch F (2011) Eyes wide open: a critical review of sphere-formation as an assay for stem cells. Cell Stem Cell 8:486-498.

Peters S, Adjei AA, Gridelli C, Reck M, Kerr K, and Felip E; ESMO Guidelines Working Group (2012) Metastatic non-small-cell lung cancer (NSCLC): ESMO Clinical Practice Guidelines for diagnosis, treatment and follow-up. Ann Oncol 23 (Suppl 7):vii56-vii64.

Phiboonchaiyanan PP, Kiratipaiboon C, and Chanvorachote P (2016) Ciprofloxacin mediates cancer stem cell phenotypes in lung cancer cells through caveolin-1dependent mechanism. Chem Biol Interact 250:1-11.

Picon-Ruiz M, Pan C, Drews-Elger K, Jang K, Besser AH, Zhao D, Morata-Tarifa C, Kim M, Ince TA, Azzam DJ, et al. (2016) Interactions between adipocytes and breast cancer cells stimulate cytokine production and drive Src/Sox2/miR-302bmediated malignant progression. Cancer Res 76:491-504.

Qureshi-Baig K, Ullmann P, Rodriguez F, Frasquilho S, Nazarov PV, Haan S, and Letellier E (2016) What do we learn from spheroid culture systems? insights from tumorspheres derived from primary colon cancer tissue. PLoS One 11 e0146052.

Rinkenbaugh AL and Baldwin AS (2016) The NF-кB pathway and cancer stem cells. Cells 5:16.

Rota LM, Lazzarino DA, Ziegler AN, LeRoith D, and Wood TL (2012) Determining mammosphere-forming potential: application of the limiting dilution analysis. $J$ Mammary Gland Biol Neoplasia 17:119-123.

Sarkar S, Döring A, Zemp FJ, Silva C, Lun X, Wang X, Kelly J, Hader W, Hamilton M, Mercier P, et al. (2014) Therapeutic activation of macrophages and microglia to suppress brain tumor-initiating cells. Nat Neurosci 17:46-55.

Shaheen S, Ahmed M, Lorenzi F, and Nateri AS (2016) Spheroid-formation (colonosphere) assay for in vitro assessment and expansion of stem cells in colon cancer. Stem Cell Rev 12:492-499.
Singh S, Trevino J, Bora-Singhal N, Coppola D, Haura E, Altiok S, and Chellappan SP (2012) EGFR/Src/Akt signaling modulates Sox2 expression and self-renewal of stem-like side-population cells in non-small cell lung cancer. Mol Cancer 11:73.

Song JX, Shaw PC, Sze CW, Tong Y, Yao XS, Ng TB, and Zhang YB (2010) Chrysotoxine, a novel bibenzyl compound, inhibits 6-hydroxydopamine induced apoptosis in $\mathrm{SH}-\mathrm{SY} 5 \mathrm{Y}$ cells via mitochondria protection and NF-кB modulation. Neurochem Int 57:676-689.

Song JX, Shaw PC, Wong NS, Sze CW, Yao XS, Tang CW, Tong Y, and Zhang YB (2012) Chrysotoxine, a novel bibenzyl compound selectively antagonizes $\mathrm{MPP}^{+}$, but not rotenone, neurotoxicity in dopaminergic SH-SY5Y cells. Neurosci Lett 521: 76-81.

Summy JM and Gallick GE (2003) Src family kinases in tumor progression and metastasis. Cancer Metastasis Rev 22:337-358.

Thakur R, Trivedi R, Rastogi N, Singh M, and Mishra DP (2015) Inhibition of STAT3, FAK and Src mediated signaling reduces cancer stem cell load, tumorigenic potential and metastasis in breast cancer. Sci Rep 5:10194.

Tian Y, Jia X, Wang S, Li Y, Zhao P, Cai D, Zhou Z, Wang J, Luo Y, and Dong M (2014) SOX2 oncogenes amplified and operate to activate AKT signaling in gastric cancer and predict immunotherapy responsiveness. J Cancer Res Clin Oncol 140: 1117-1124.

Timeus F, Crescenzio N, Fandi A, Doria A, Foglia L, and Cordero di Montezemolo L (2008) In vitro antiproliferative and antimigratory activity of dasatinib in neuroblastoma and Ewing sarcoma cell lines. Oncol Rep 19:353-359.

Vazquez-Santillan K, Melendez-Zajgla J, Jimenez-Hernandez L, Martínez-Ruiz G, and Maldonado V (2015) NF-кB signaling in cancer stem cells: a promising therapeutic target? Cell Oncol (Dordr) 38:327-339.

Wang X, Ji X, Chen J, Yan D, Zhang Z, Wang Q, Xi X, and Feng Y (2014) SOX2 enhances the migration and invasion of ovarian cancer cells via Src kinase. PLoS One 9:e99594.

Weiswald LB, Bellet D, and Dangles-Marie V (2015) Spherical cancer models in tumor biology. Neoplasia 17:1-15.

Xiang R, Liao D, Cheng T, Zhou H, Shi Q, Chuang TS, Markowitz D, Reisfeld RA, and Luo Y (2011) Downregulation of transcription factor SOX2 in cancer stem cells suppresses growth and metastasis of lung cancer. $\mathrm{Br} J$ Cancer 104: 1410-1417.

Yang N, Hui L, Wang Y, Yang H, and Jiang X (2014) SOX2 promotes the migration and invasion of laryngeal cancer cells by induction of MMP-2 via the PI3K/Akt/mTOR pathway. Oncol Rep 31:2651-2659.

Yongsanguanchai N, Pongrakhananon V, Mutirangura A, Rojanasakul Y, and Chanvorachote $\mathrm{P}$ (2015) Nitric oxide induces cancer stem cell-like phenotypes in human lung cancer cells. Am J Physiol Cell Physiol 308:C89-C100.

Zhang J, Kalyankrishna S, Wislez M, Thilaganathan N, Saigal B, Wei W, Ma L, Wistuba 2nd, Johnson FM, and Kurie JM (2007) SRC-family kinases are activated in non-small cell lung cancer and promote the survival of epidermal growth factor receptor-dependent cell lines. Am J Pathol 170:366-376.

Address correspondence to: Pithi Chanvorachote, Department of Pharmacology and Physiology, Faculty of Pharmaceutical Sciences, Chulalongkorn University, Pathumwan, Bangkok 10330, Thailand. E-mail: pithi_chan@ yahoo.com 